\title{
Forecasting wheat and barley crop production in arid and semi-arid regions using remotely sensed primary productivity and crop phenology: a case study in Iraq
}

Correspondence Author Email: shq1g12@soton.ac.uk

\begin{abstract}
Crop production and yield estimation using remotely sensed data have been studied widely, but such information is generally scarce in arid and semi-arid regions. In these regions, inter-annual variation in climatic factors (such as rainfall) combined with anthropogenic factors (such as civil war) pose major risks to food security. Thus, an operational crop production estimation and forecasting system is required to help decision-makers to make early estimates of potential food availability. Data from NASA's MODIS with official crop statistics were combined to develop an empirical regression-based model to forecast winter wheat and barley production in Iraq. The study explores remotely sensed indices representing crop productivity over the crop growing season to find the optimal correlation with crop production. The potential of three different remotely sensed indices, and information related to the phenology of crops, for forecasting crop production at the governorate level was tested and their results were validated using the leave-one-year-out approach. Despite testing several methodological approaches, and extensive spatio-temporal analysis, this paper depicts the difficulty in estimating crop yield on an annual base using current satellite low-resolution data. However, more precise estimates of crop production were possible. The result of the current research implies that the date of the maximum vegetation index (VI) offered the most accurate forecast of crop production with an average $\mathrm{R} 2=0.70$ compared to the date of MODIS EVI (Avg R2=0.68) and a NPP (Avg R2=0.66). When winter wheat and barley production were forecasted using NDVI, EVI and NPP and compared to official statistics, the relative error ranged from -20 to $20 \%,-45$ to $28 \%$ and -48 to $22 \%$, respectively. The research indicated that remotely sensed indices could characterize and forecast crop production more accurately than simple cropping area, which was treated as a null model against which to evaluate the proposed approach.
\end{abstract}


Keywords: Vegetation phenology, crop yield/production forecasting, MODIS, NDVI, EVI, NPP and Iraq

\section{Introduction}

\subsection{Challenges of food security in arid and semi-arid regions}

At present, $15 \%$ of the Earth's population (841 million people) live in arid and semi-arid regions, of which about 524 million live in semi-arid regions (Barakat, 2009). Rapid population growth (Barakat, 2009) together with rising living standards in arid and semi-arid regions imply that more food will be required to meet the demands of these populations. This is a major driver of land conversion to agricultural and grazing land within these regions (Millennium Ecosystem Assessment, 2005). Therefore, crop production forecasting is potentially a crucial tool for tackling food insecurity in arid and semi-arid regions as well as an essential input to decision-making for agricultural insurance. However, this is one of the most challenging tasks in crop research because of the highly variable climate in arid and semi-arid regions.

In many parts of the world, wheat and barley are major grain crops and their production influences local food security (Macdonald and Hall 1980; FAO 2003a). At the global scale, more than $541 \times 10^{10}$ and $49 \times 10^{10} \mathrm{~m}^{2}$ (harvested area) was dedicated to growing wheat and barley, respectively, of which over $649 \times 10^{6}$ and $130 \times 10^{6}$ MT of cereal was produced in 2013 (FAOSTAT, 2013). Furthermore, wheat and barley play an essential role in international trade, and it has been reported that food shortages are commonly attributable to a lack of wheat and barley (d'Amour et al. 2016; Fellmann et al. 2014; Mellor, 1972). In both developing and developed country contexts, timely and accurate estimation of wheat and barley yield and production before harvesting are, therefore, vital at different governance levels including regional, national and international levels. Such forecasts could increase regional food security, through improved policy setting and local decision-making, as well as playing a crucial role in informing international markets (Justic and Becker-Reshef, 2007).

In part, due to the likelihood of unfavourable climatic events across many arid and semi-arid regions of the world, local communities are often food insecure and at risk of famine. Weather extremes such 
as droughts and floods can have a direct impact on food production and can negatively affect the storage and distribution of food (Haile 2005; Wheeler and von Braun 2013). For example, in Turkey, the drought in 2008-2009 caused sizeable declines in crop yields, which cost $\$ 1-2$ billion and 435,000 farmers were affected while in Iraq the total wheat production was reduced by $45 \%$ compared to the previous year (USDA FAS, 2008a).

Another factor which makes many of the regions in the world food insecure, and in particular regions in the Middle East such as Iraq, is political instability and its consequences. War and conflict can damage the economy and incomes, and cause disease, forced immigration, refugee populations, a collapse of social trust, and severe food insecurity (WFP, 2011). Conflict was the main cause of undernourishment in more than half of the Middle East countries in the 1990s (FAO, 2003b). The main drivers of more than $35 \%$ of food emergencies from 1992 to 2003 were economic issues and conflict; in contrast, this value was $15 \%$ in the period between 1986 and 1991 (FAO, 2003a). Therefore, timely monitoring and forecasting of crop production is especially required in regions where the potential for drought occurs in the context of conflict.

Over the last decade crop production in Iraq has been negatively affected by both natural and anthropogenic events. For instance, Iraq was involved in a war 'Post-Gulf' mainly to oppose the previous regime. Due to political instability during the war, many farmers either abandoned their land or were unable to grow their crops effectively, and this affected overall crop production in the country. In addition, due to its geographical location, Iraq is affected by irregularity in precipitation resulting in the frequent occurrence of droughts. Both factors have made the region vulnerable to irregularities in food production.

\subsection{Review of crop yield forecasting}

A wide range of the techniques to estimate and forecast crop yield have been employed during the past decades with different degrees of utility and accuracy. Crop yield estimation in many countries still relies on traditional approaches based on data collection on the ground and reporting (crop cutting experiments). Such data are frequently time consuming to obtain, costly and prone to large errors because of incomplete ground observations, leading to uncertain crop area estimation and crop yield 
assessment (Reynolds et al. 2000). Crop yield can also be forecasted through either statistical or agronomic models based on historical weather, crop management and crop production data. In some countries, weather data have been employed to monitor and forecast crop production (Andarzian et al. 2008; Liu and Kogan 2002; Paul et al. 2013; de Wit and Boogaard 2001). Missing data, a lack of continuity in weather data and the sparse spatial distribution of ground weather stations for a large diverse crop area limit the utility of these approaches (Liu and Kogan 2002; Dadhwall and Ray 2000; de Wit and Boogaard 2001).

With the development of satellite sensors, there has been increased interest in utilizing satellite remotely sensed data for crop monitoring and crop production forecasting due its ability to provide data synoptically, with greater spatial coverage, potentially at the global scale. In addition, remote sensing can provide timely (and potentially real-time) and objective data on crop growth at relatively low cost. In this regard, the NDVI has a long history of use for monitoring crop condition and estimating crop yield (Doraiswamy et al. 2004; Groten, 1993; Kastens et al. 2005). Either remotely sensed data can be used as an input to crop simulation models or remotely sensed biophysical variables measured within-season can be used as a surrogate of crop production for use in monitoring and forecasting. One such approach involves biophysical crop simulation models, which are calibrated and driven through remotely sensed information on crop characteristics within-season. Examples of crop simulation models include the World Food Studies (WOFOST) (Vandiepen et al. 1989), Simulateur mulTIdisciplinaire pour les Cultures Standard (STICS) (Brisson et al. 1998) and Crop Systems Simulation (CROPSYST) models (Van Evert and Campbell, 1994). These models assimilate several factors that affect crop growth and development such as temperature, wind, water availability and type of management practice which lead them to be capable of capturing soilenvironment-plant interactions (Moriondo et al. 2007). However, the high computational and data demands of these models make them generally difficult to use in some regions for which data are sparse. In addition, their complexity, method of analysis and large number of tuning parameters have led them to be impractical, particularly capturing field level information in a heterogeneous landscape. The most widely used approach to estimate crop yield at the regional scale is based on simple regression between a satellite-derived vegetation index within-season and actual crop yield (Wall et 
al. 2008). A linear regression model was established by Hamar et al (1996) to estimate wheat and corn yield at the county level based on vegetation indices derived from Landsat multispectral scanner system (MSS) data in Hungary. Similarly, a relatively large correlation between wheat yield and NDVI integrated over the entire growing season, and with late season NDVI, was observed at the regional and farm scales in Montana for the years 1989-1997 (Labus et al. 2002). Ren et al. (2008) found the largest correlation between county level winter wheat production and the spatial accumulation of MODIS-NDVI, 40 days ahead of harvest time, and the accuracy was within $10 \%$ of official statistics in Shandong Province, China. NDVI, normalized difference water index (NDWI) and a two-band variant of the enhanced vegetation index (EVI2) were employed to predict the US crop yield, and showed that including crop phenology-related information increased the regression model accuracy (Bolton and Friedl 2013). The study indicated that the best dates to predict crop yield were 65-75 days and 80 days after the MODIS derived green up for maize and soybean, respectively for the US.

Because statistical regression-based approaches model the empirical relation between a satellitederived vegetation index and historical yield data, the model is typically localized and cannot be generalised to other areas readily (Moriondo et al. 2007; Doraiswamy et al. 2003). In addition, if photosynthetic capacity at the time of measurement is not the main driver of the eventual crop yield, forecasting may be inaccurate (Becker-Reshef et al. 2010). However, the low demand for data and simplicity of implementation has led to regression being the most widely used approach for estimating crop yield.

There have been limited attempts to monitor and forecast crops in arid and semi-arid regions based on remotely sensed data. Forecasts of crop production and yield are needed by policy-makers, the academic community and crop insurance companies. In particular, due to population increases, regional instability and natural disasters, there is a growing need for micro-level forecasting of crop production and yield over Iraq. This forecasting should warn local authorities about potential changes in crop production and yield, leading to appropriate import and export decisions. In addition, remote sensing crop yield methods have been developed for other parts of the world, but not for arid and semi-arid regions such as Iraq. Here, we aim to explore if such methods can be applied to arid and 
semi-arid regions. Therefore, the current research aims to evaluate the potential of MODIS-derived measures of greenness and productivity, and information related to the phenology of crops to estimate crop production and yield in arid and semi-arid regions using Iraq as a case study.

\section{Methods}

\subsection{Study area}

Iraq is predominantly an agricultural country, and has long been recognised as one of the oldest agricultural countries in the world (Figure 1a). Although the agricultural sector is no longer the most significant contributor to the country's economy, but rather is important as a source of employment and livelihood. For example, the agricultural sector in Iraq provides employment to $20 \%$ of the population and one third of the total population resides in rural areas where agriculture is the main source of livelihoods (FAO 2012). Despite internal and external support, Iraq has a high level of food insecurity and has made slow progress towards improving this situation. For example, the proportion of undernourished in the total population increased from 8\% to 23\% between 1990 to 2015 (FAO, IFAD and WFP. 2015)

Of 3.5 to 4 million ha cultivated crops, $70 \%$ to $85 \%$ is dedicated to plant wheat and barley in any given year (Schnepf 2004; Gibson et al. 2012). Figure (2) shows the wheat and barley production over the study period. One third of the country's cereals are produced under rain-fed conditions and the remaining cereal production occurs within irrigated areas between, and along, the Tigris and Euphrates rivers (FAO 2008). 

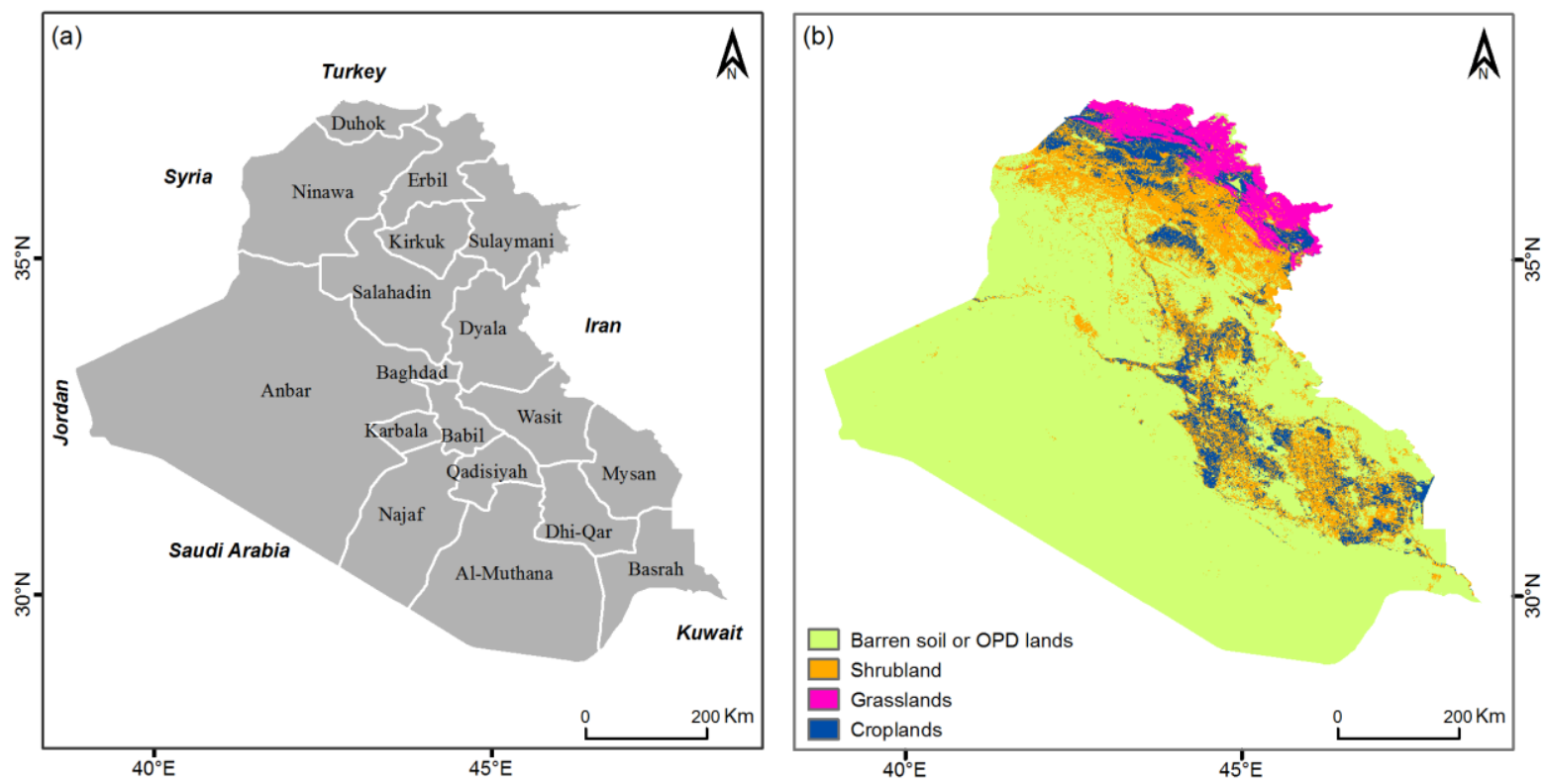

Figure 1. Maps (a) study area (Iraq is composed of 18 governorates) and (b) a phenology-based classification of land cover in 2006 with a spatial resolution of $250 \mathrm{~m}$ (Qader et al. 2016).

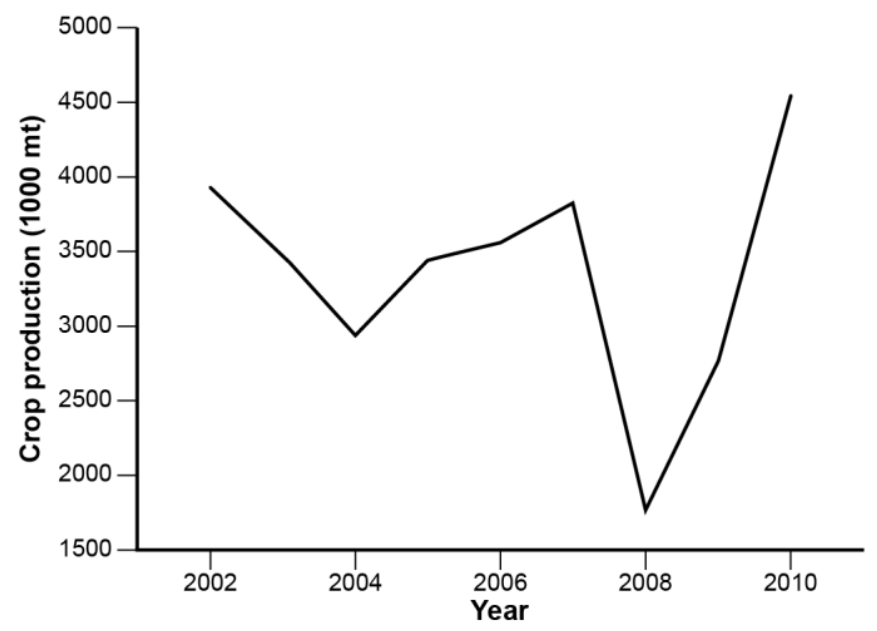

Figure 2. Wheat and barley production from 2002 to 2010.

\subsection{Data and pre-processing}

A time-series of 8-day composites of the MODIS land surface reflectance product (MOD09Q1) at 250 $\mathrm{m}$ and MOD09A1 at $500 \mathrm{~m}$ spatial resolution from 2002 to 2010 were used to estimate NDVI, EVI, and the seasonal phenological parameters. The data were downloaded from NASA's Land Processes Distributed Active Archive Centre (LP DAAC) (https://lpdaac.usgs.gov/data_access). The NDVI has been used widely for crop monitoring and the production of agricultural statistics (Hatfield and 
Prueger, 2010; Becker-Reshef et al. 2010; Benedetti and Rossini, 1993). NDVI tends to saturate at large biomass, whereas EVI has increased sensitivity in this region (Huete, 1997). In addition, by incorporating the reflectance in the blue band of the electromagnetic spectrum, EVI reduces the impact of the soil background and atmosphere (Rocha and Shaver, 2009; Jiang et al. 2008; Huete et al. 1997). For crop yield forecasting, both indices have been applied widely (Kouadio and Newlands, 2014; Kogan et al. 2012; Moriondo et al. 2007; Doraiswamy et al. 2005). In the current research, the NDVI and EVI were computed from the above MODIS products as the available MODIS NDVI and EVI are available at the temporal resolution of 16-day.

The information in the quality assurance (QA) layer in the MOD09Q1 and MOD09A1 products was used to remove contaminated pixels due to sensor effects such as different orbits, adjacency, band quality, and MODLAND QA, and non-sensor effects such as cloud state and atmospheric noise (atmospherically corrected and clear cloud state). Then, for each time step (compositing period) the NDVI and EVI were calculated from the surface reflectance data. A temporal moving average window function was applied to correct errors in specific weeks, a linear interpolation approach was applied for gap filling, and for the purpose of data smoothing the current study used Fourier-based smoothing (Dash et al. 2010; Qader et al. 2015).

In addition to the vegetation indices, the MODIS Net Primary Productivity (NPP) product was also employed as a predictor of crop production and yield. NPP plays a crucial role in studies of global vegetation changes, particularly for global biomass mapping and crop yield estimation (Jianqiang et al. 2008). Satellite-derived NPP has been demonstrated to have a large correlation with regional crop production. For example, less than $4 \%$ error was recorded between forecasted yield and actual yield using NPP extracted from TM images in the Yaqui Valley, Mexico (Lobell et al. 2003). In north China, a model was fitted to the relation between winter wheat yield and a function of MODIS NPP, and the absolute error of estimated yield was $232.7 \mathrm{~kg}$.ha ${ }^{-1}$ with a relative error of $4.28 \%$ (Jianqiang et al. 2008).

NPP (MOD17A3) is an annual product provided from 2002 to 2010 with a spatial resolution of 1000 m (https://lpdaac.usgs.gov/data_access). To retain the best quality pixels, the information in the QA flag layer was also applied for this product (pixels falling into the following categories, perennial salt 
or inland fresh water body cover type, perennial snow or ice cover type, permanent wetlands/inundated marshland, urban/built up and unclassified pixel were excluded) (https://lpdaac.usgs.gov/data_access).

\subsection{Crop statistics data}

For winter wheat and barley, data on the total area planted, total area harvested, production and yield from 2002-2010 were obtained from Statistics Iraq (COSIT 2011). In Iraq, agricultural activities are managed through agricultural directors at the governorate level (Abi-Ghanem et al. 2009). Thus, official governorate statistics on agricultural activities such as crop yield, production and area are aggregated to the governorate level. Iraq consists of 18 governorates (Figure 1).

\subsection{Crop map}

To allow utilization of MODIS VIs and NPP in crop production and yield forecasting, it is necessary to identify the areas under cropping. The crop map for the current research is based on previous work (Qader et al. 2016) in which a phenology-based classification approach was developed to map annually the dominant vegetation land cover types over Iraq such as cropland, grassland and shrubland (Figure 1b). The approach employed several phenological parameters together with elevation data to discriminate the dominant vegetation land cover types using a support vector machine (SVM) classifier. Overall, the accuracies were generally $>85 \%$ with relatively high Kappa coefficients $(>0.86)$ across all the classified land cover types. To make all the datasets comparable, the ArcGIS software was employed to resample the crop map data $(250 \mathrm{~m})$ to the spatial resolution of the MODIS EVI (500 m) and MODIS NPP (1000 m) using the nearest neighbour resampling approach.

\subsection{The threshold for the indices utilized to forecast crop production and yield}

Several studies indicated that the correlation between final crop production (and yield) and VIs changes through the crop growing season (Doraiswamy et al. 2005; Ren at al. 2008; Huang et al. 2013). Therefore, using crop phenology can have a significant benefit for remote sensing-based crop 
yield models as crop yields change as a function of time throughout the growing season (Mkhabela et al. 2011; Sakamoto et al. 2013; Bolton and Friedl 2013; Meng et al. 2014). Crop phenology varies spatially and inter-annually and, therefore, forecasting of crop yield based on a VI at a fixed calendar date is not optimal (Bolton and Friedl 2013). In the current research, three different approaches were applied to find the phenological parameters, which have the optimal coefficient of determination with crop production and yield at the governorate level in Iraq (Figure 3).

The maximum NDVI and EVI were estimated from the smoothed time-series data, which is equal to the peak value for each growing season, and from these maxima, seven (8-day) composite values before and after each maximum were defined. Using this information, time-series values of NDVI and EVI with an 8-day interval, which starts at the seventh 8-day composite before maximum $\left(\operatorname{Max}_{\mathrm{b} 7}\right)$ and ends at the seventh 8-day composite after maximum $\left(\operatorname{Max}_{\mathrm{a} 7}\right)$ over the growing season were extracted (Figure 3).

Generally, three different types of VI-related variables were suggested in the literature to correlate with final yield such as the original value (Rojas 2007; Esquerdo et al. 2011), integrated value over the growing season (Mkhabela et al. 2005; Wall et al. 2008; Balaghi et al. 2008) and average value (Boken, Shaykewich 2002; Mkhabela et al. 2005). Some studies (e.g. Ren et al. 2008; Becker-Reshef et al. 2010) regressed crop production statistics at the county level on spatially-accumulated NDVI. Other studies (e.g. Tucker et al. 1980; Rojas, 2007) showed that seasonally integrated VIs, could forecast production more accurately than single measures. It has also been demonstrated that VIs around the time of maximum have a large correlation with final yield (Tucker et al. 1980; Benedetti and Rossini 1993). Therefore, three different approaches were employed in the current research:

1- Approach 1: spatial sum of the single parameter (original value) from $\operatorname{Max}_{b 7}$ to $\operatorname{Max}_{a 7}$ at the governorate level (Figure 3 and Table 1).

2- Approach 2: cumulative, integrated spatial sum of the parameters from $\operatorname{Max}_{\mathrm{b} 7}$ to $\operatorname{Max}_{\mathrm{a} 7}$ over the growing season (Figure 3 and Table 1).

3- Approach 3: integrated spatial sum of the vegetation indices for four composite periods before and four composite periods after the maximum value (Figure 3 and Table 1). 


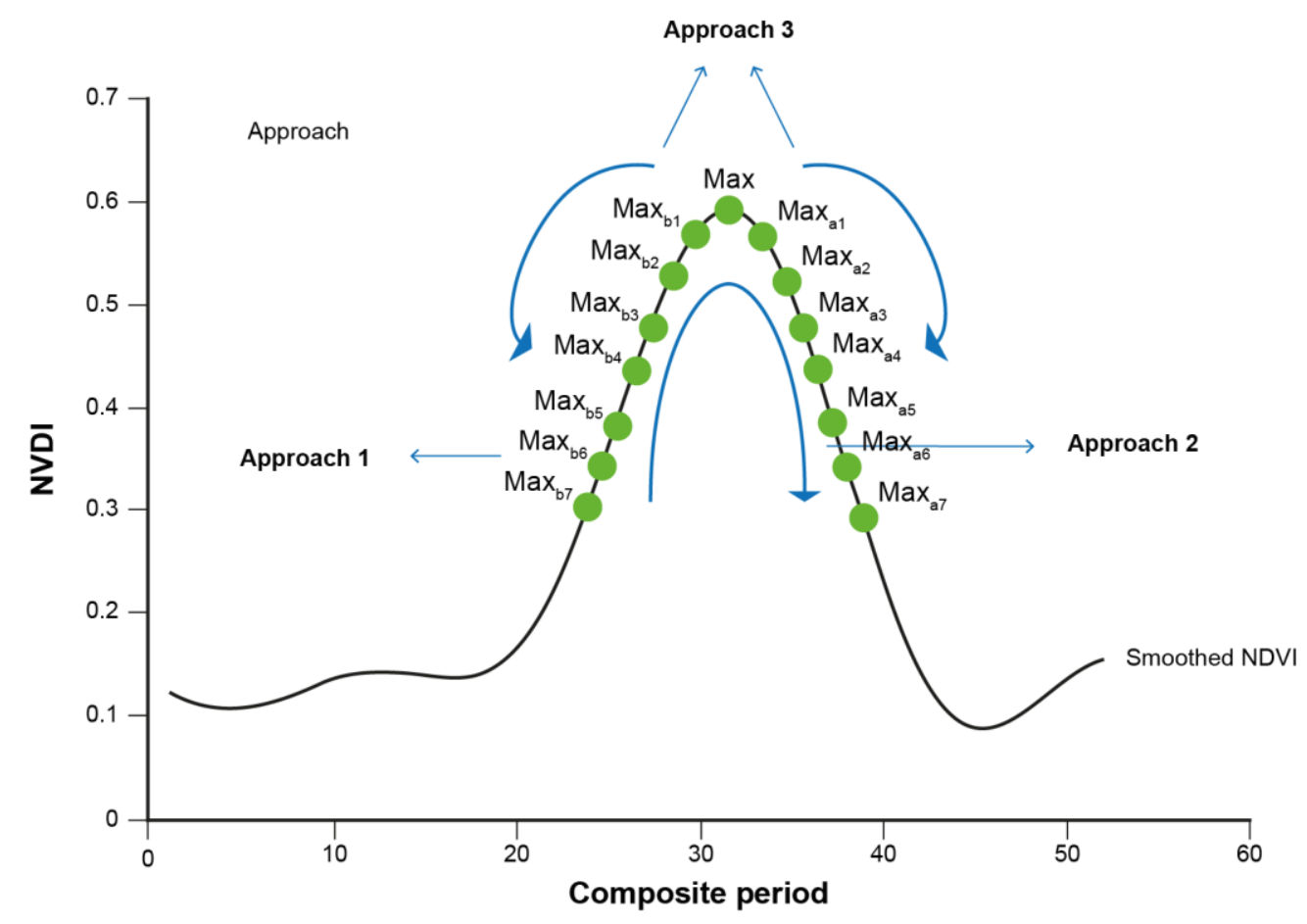

Figure 3. The proposed three approaches to determine the phenological parameters which have the largest coefficient of determination with crop production or yield at the governorate level.

The three algorithms search during the growing season to find the time of the phenological event that has the largest coefficient of determination with crop production or yield at the governorate level. The description of the VIs and their calculation are presented in Table 1. However, as NPP is an annual product, only one spatial sum NPP value can be correlated with crop production or yield at the governorate level. The main purpose of applying three different approaches is to determine which indices and phenological parameters can estimate crop production or yield most accurately in advance. To depict the impact of the spatial resolution on the spatial coefficient of determination between biophysical variables and crop production at the governorate level, the NDVI $(250 \mathrm{~m})$ data was up scaled to $500 \mathrm{~m}$ and $1000 \mathrm{~m}$ using the nearest neighbour approach to be comparable with the EVI $(500 \mathrm{~m})$ and NPP $(1000 \mathrm{~m})$ data which can show the impact of spatial resolution on crop production estimation.

Table 1. Description of the employed variables, equations, and NDVI as an example. 


\begin{tabular}{|c|c|c|c|c|c|}
\hline \multirow[t]{2}{*}{$\begin{array}{c}\text { NDVI } \\
\text { variables }\end{array}$} & \multicolumn{5}{|c|}{ Description of equations } \\
\hline & Approach one & & Approach two & & Approach three \\
\hline $\mathrm{NDVI}_{\operatorname{maxb} 7}$ & $\begin{array}{l}\text { The seventh 8-day } \\
\text { composite before } \\
\text { NDVI }_{\max }\end{array}$ & $\mathrm{NDVI}_{\operatorname{maxb} 7}$ & $\mathrm{NDVI}_{\operatorname{maxb} 7}$ & & \\
\hline $\mathrm{NDVI}_{\operatorname{maxb} 6}$ & $\begin{array}{l}\text { The sixth 8-day } \\
\text { composite before } \\
\text { NDVI }_{\max }\end{array}$ & $\mathrm{NDVI}_{\operatorname{maxb7-b6}}$ & $\left(\mathrm{NDVI}_{\operatorname{maxb} 7}+\mathrm{NDVI}_{\operatorname{maxb} 6}\right)$ & & \\
\hline $\mathrm{NDVI}_{\operatorname{maxb} 5}$ & $\begin{array}{l}\text { The fifth 8-day } \\
\text { composite before } \\
\text { NDVI }_{\max }\end{array}$ & $\mathrm{NDVI}_{\operatorname{maxb7-b5}}$ & $\begin{array}{l}\left(\mathrm{NDVI}_{\operatorname{maxb} 7}+\mathrm{NDVI}_{\operatorname{maxb} 6}+\right. \\
\left.\mathrm{NDVI}_{\operatorname{maxb} 5}\right)\end{array}$ & & \\
\hline $\mathrm{NDVI}_{\operatorname{maxb} 4}$ & $\begin{array}{l}\text { The fourth 8-day } \\
\text { composite before } \\
\text { NDVI }_{\max }\end{array}$ & $\mathrm{NDVI}_{\operatorname{maxb7-b4}}$ & $\begin{array}{l}\left(\mathrm{NDVI}_{\operatorname{maxb} 7}+\mathrm{NDVI}_{\operatorname{maxb} 6}+\right. \\
\left.\mathrm{NDVI}_{\operatorname{maxb} 5}+\mathrm{NDVI}_{\operatorname{maxb} 4}\right)\end{array}$ & $\mathrm{NDVI}_{\max -\mathrm{b} 4}$ & $\begin{array}{l}\left(\mathrm{NDVI}_{\max }+\mathrm{NDVI}_{\operatorname{maxb} 1}+\right. \\
\mathrm{NDVI}_{\max 2}+\mathrm{NDVI}_{\operatorname{maxb3} 3}+ \\
\left.\mathrm{NDVI}_{\operatorname{maxb} 4}\right)\end{array}$ \\
\hline $\mathrm{NDVI}_{\operatorname{maxb} 3}$ & $\begin{array}{l}\text { The third 8-day } \\
\text { composite before } \\
\text { NDVI }_{\max }\end{array}$ & $\mathrm{NDVI}_{\operatorname{maxb7-b3}}$ & $\begin{array}{l}\left(\mathrm{NDVI}_{\operatorname{maxb}}+\mathrm{NDVI}_{\operatorname{maxb} 6}+\right. \\
\mathrm{NDVI}_{\operatorname{maxb} 5}+\mathrm{NDVI}_{\operatorname{maxb} 5}+ \\
\left.\mathrm{NDVI}_{\operatorname{maxb} 3}\right)\end{array}$ & $\mathrm{NDVI}_{\max -\mathrm{b} 3}$ & $\begin{array}{l}\left(\mathrm{NDVI}_{\max }+\mathrm{NDVI}_{\operatorname{maxb} 1}+\right. \\
\left.\mathrm{NDVI}_{\operatorname{maxb2}}+\mathrm{NDVI}_{\operatorname{maxb} 3}\right)\end{array}$ \\
\hline $\mathrm{NDVI}_{\operatorname{maxb} 2}$ & $\begin{array}{l}\text { The second 8-day } \\
\text { composite before } \\
\text { NDVI }_{\operatorname{maxc}}\end{array}$ & $\mathrm{NDVI}_{\operatorname{maxb7-b2}}$ & $\begin{array}{l}\left(\mathrm{NDVI}_{\operatorname{maxb} 7}+\mathrm{NDVI}_{\operatorname{maxb6}}+\right. \\
\mathrm{NDVI}_{\operatorname{maxb} 5}+\mathrm{NDVI}_{\operatorname{maxb} 4}+ \\
\left.\mathrm{NDVI}_{\operatorname{maxb} 3}+\mathrm{NDVI}_{\operatorname{maxb} 2}\right)\end{array}$ & $\mathrm{NDVI}_{\text {max-b2 }}$ & $\begin{array}{l}\left(\mathrm{NDVI}_{\max }+\mathrm{NDVI}_{\operatorname{maxb} 1}+\right. \\
\left.\mathrm{NDVI}_{\operatorname{maxb} 2}\right)\end{array}$ \\
\hline $\mathrm{NDVI}_{\operatorname{maxb} 1}$ & $\begin{array}{l}\text { The first 8-day } \\
\text { composite before } \\
\text { NDVI }_{\max }\end{array}$ & $\mathrm{NDVI}_{\operatorname{maxb7-b1}}$ & $\begin{array}{l}\left(\mathrm{NDVI}_{\operatorname{maxb} 7}+\mathrm{NDVI}_{\operatorname{maxb} 6}+\right. \\
\mathrm{NDVI}_{\operatorname{maxb} 5}+\mathrm{NDVI}_{\operatorname{maxb} 4}+ \\
\mathrm{NDVI}_{\operatorname{maxb} 3}+\mathrm{NDVI}_{\operatorname{maxb} 2}+ \\
\left.\mathrm{NDVI}_{\operatorname{maxb} 1}\right)\end{array}$ & $\mathrm{NDVI}_{\text {max-b1 }}$ & $\left(\mathrm{NDVI}_{\max }+\mathrm{NDVI}_{\operatorname{maxb1}}\right)$ \\
\hline $\mathrm{NDVI}_{\max }$ & Maximum NDVI & $\begin{array}{l}\mathrm{NDVI}_{\operatorname{maxb} 7-} \\
\max \end{array}$ & $\begin{array}{l}\left(\mathrm{NDVI}_{\operatorname{maxb} 7}+\mathrm{NDVI}_{\operatorname{maxb} 6}+\right. \\
\mathrm{NDVI}_{\operatorname{maxb} 5}+\mathrm{NDVI}_{\operatorname{maxb} 4}+ \\
\mathrm{NDVI}_{\operatorname{maxb} 3}+\mathrm{NDVI}_{\operatorname{maxb} 2}+ \\
\left.\mathrm{NDVI}_{\operatorname{maxb} 1}+\mathrm{NDVI}_{\max }\right)\end{array}$ & $\mathrm{NDVI}_{\max }$ & $\mathrm{NDVI}_{\max }$ \\
\hline $\mathrm{NDVI}_{\operatorname{maxa} 1}$ & $\begin{array}{l}\text { The first 8-day } \\
\text { composite after } \\
\text { NDVI }_{\max }\end{array}$ & $\mathrm{NDVI}_{\operatorname{maxb7-a1}}$ & $\begin{array}{l}\left(\mathrm{NDVI}_{\operatorname{maxb} 7}+\mathrm{NDVI}_{\operatorname{maxb} 6}+\right. \\
\mathrm{NDVI}_{\operatorname{maxb} 5}+\mathrm{NDVI}_{\operatorname{maxb} 4}+ \\
\mathrm{NDVI}_{\operatorname{maxb} 3}+\mathrm{NDVI}_{\operatorname{maxb} 2}+ \\
\mathrm{NDVI}_{\operatorname{maxb1}}+\mathrm{NDVI}_{\max }+ \\
\left.\mathrm{NDVI}_{\operatorname{maxa}}\right)\end{array}$ & $\mathrm{NDVI}_{\text {max-a1 }}$ & $\left(\mathrm{NDVI}_{\max }+\mathrm{NDVI}_{\operatorname{maxa}}\right)$ \\
\hline $\mathrm{NDVI}_{\operatorname{maxa} 2}$ & $\begin{array}{l}\text { The second 8-day } \\
\text { composite after } \\
\text { NDVI }_{\operatorname{maxc}}\end{array}$ & $\mathrm{NDVI}_{\operatorname{maxb} 7-\mathrm{a} 2}$ & $\begin{array}{l}\left(\mathrm{NDVI}_{\operatorname{maxb} 7}+\mathrm{NDVI}_{\operatorname{maxb} 6}+\right. \\
\mathrm{NDVI}_{\operatorname{maxb} 5}+\mathrm{NDVI}_{\operatorname{maxb} 4}+ \\
\mathrm{NDVI}_{\operatorname{maxb} 3}+\mathrm{NDVI}_{\operatorname{maxb} 2}+ \\
\mathrm{NDVI}_{\operatorname{maxb} 1}+\mathrm{NDVI}_{\max }+ \\
\mathrm{NDVI}_{\operatorname{maxa}}+\mathrm{NDVI}_{\operatorname{maxa} 2} \text { ) }\end{array}$ & $\mathrm{NDVI}_{\text {max-a2 }}$ & $\begin{array}{l}\left(\mathrm{NDVI}_{\max }+\mathrm{NDVI}_{\operatorname{maxa} 1}+\right. \\
\left.\mathrm{NDVI}_{\operatorname{maxa} 2}\right)\end{array}$ \\
\hline $\mathrm{NDVI}_{\text {maxa3 }}$ & $\begin{array}{l}\text { The third 8-day } \\
\text { composite after } \\
\text { NDVI }_{\max }\end{array}$ & $\mathrm{NDVI}_{\operatorname{maxb} 7-\mathrm{a} 3}$ & $\begin{array}{l}\left(\mathrm{NDVI}_{\operatorname{maxb} 7}+\mathrm{NDVI}_{\operatorname{maxb} 6}+\right. \\
\mathrm{NDVI}_{\operatorname{maxb} 5}+\mathrm{NDVI}_{\operatorname{maxb} 4}+ \\
\mathrm{NDVI}_{\operatorname{maxb} 3}+\mathrm{NDVI}_{\operatorname{maxb} 2}+ \\
\mathrm{NDVI}_{\operatorname{maxb} 1}+\mathrm{NDVI}_{\max }+ \\
\mathrm{NDVI}_{\operatorname{maxa}}+\mathrm{NDVI}_{\operatorname{maxa} 2}+ \\
\left.\mathrm{NDVI}_{\operatorname{maxa} 3}\right)\end{array}$ & $\mathrm{NDVI}_{\text {max-a3 }}$ & $\begin{array}{l}\left(\mathrm{NDVI}_{\max }+\mathrm{NDVI}_{\operatorname{maxa} 1}+\right. \\
\left.\mathrm{NDVI}_{\operatorname{maxa} 2}+\mathrm{NDVI}_{\max 3}\right)\end{array}$ \\
\hline $\mathrm{NDVI}_{\operatorname{maxa} 4}$ & $\begin{array}{l}\text { The fourth 8-day } \\
\text { composite after } \\
\text { NDVI }_{\max }\end{array}$ & $\mathrm{NDVI}_{\operatorname{maxb} 7-\mathrm{a} 4}$ & $\begin{array}{l}\mathrm{NDVI}_{\operatorname{maxb} 7}+\mathrm{NDVI}_{\operatorname{maxb} 6}+ \\
\mathrm{NDVI}_{\operatorname{maxb} 5}+\mathrm{NDVI}_{\operatorname{maxb} 4}+ \\
\mathrm{NDVI}_{\operatorname{maxb} 3}+\mathrm{NDVI}_{\max 2}+ \\
\mathrm{NDVI}_{\operatorname{maxb} 1}+\mathrm{NDVI}_{\max }+ \\
\mathrm{NDVI}_{\operatorname{maxa}}+\mathrm{NDVI}_{\operatorname{maxa} 2}+ \\
\left.\mathrm{NDVI}_{\max 3}+\mathrm{NDVI}_{\max 4}\right)\end{array}$ & $\mathrm{NDVI}_{\text {max-a } 4}$ & $\begin{array}{l}\left(\mathrm{NDVI}_{\max }+\mathrm{NDVI}_{\operatorname{maxa} 1}+\right. \\
\mathrm{NDVI}_{\max 2}+\mathrm{NDVI}_{\operatorname{maxa} 3}+ \\
\left.\mathrm{NDVI}_{\max 2}\right)\end{array}$ \\
\hline $\mathrm{NDVI}_{\max 5}$ & $\begin{array}{l}\text { The fifth 8-day } \\
\text { composite after } \\
\text { NDVI }_{\max }\end{array}$ & $\mathrm{NDVI}_{\operatorname{maxb} 7-\mathrm{a} 5}$ & 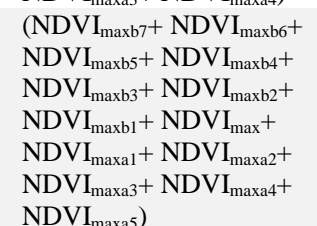 & & \\
\hline $\mathrm{NDVI}_{\max } 6$ & $\begin{array}{l}\text { The sixth 8-day } \\
\text { composite after } \\
\text { NDVI }_{\max }\end{array}$ & $\mathrm{NDVI}_{\operatorname{maxb} 7-\mathrm{a} 6}$ & 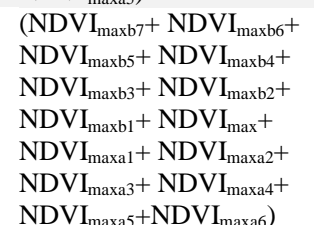 & & \\
\hline $\mathrm{NDVI}_{\max 7}$ & $\begin{array}{l}\text { The seventh 8-day } \\
\text { composite after } \\
\text { NDVI }_{\max }\end{array}$ & $\mathrm{NDVI}_{\operatorname{maxb} 7-\mathrm{a} 7}$ & 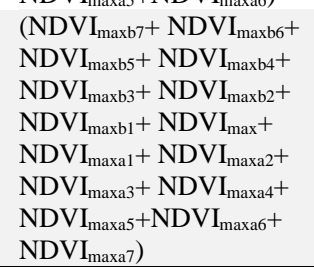 & & \\
\hline
\end{tabular}


It might be argued that production is driven mainly by crop area and using remotely sensed indices might not have much impact on increasing the accuracy of the forecast of final crop production beyond knowledge of the cropped area. Thus, we investigated the relationship between final crop production and both (i) actual crop area and (ii) estimated crop area at the governorate level from 2002 to 2010 and compared these to the results using the remotely sensed indices as predictors.

\subsection{Regression model development}

The first stage in fitting a model to forecast crop production or yield is to decide how to relate the vegetation indices (VIs) to the final production or yield modelling. Several approaches were considered in the current research to select the data in the remote sensing-based crop production or yield model:

(i) the three approaches already mentioned (Figure 3) and annual NPP

(ii) average VIs for the previous three approaches (Figure 3) and average NPP at the governorate level, and

(iv) applying the log transformation to the previous three approaches and NPP at the governorate level to improve the regression fit.

These approaches were tested in two ways; (i) the coefficient of determination was estimated between the official statistics on production or yield and transforms of the VIs among all governorates within one year (Spatial analysis), and (ii) the same based on each governorate during the period (temporal analysis).

\subsection{Model validation}

Validating performance is an essential part of the remote sensing-based crop production or yield model. In this regard, several approaches to validate the model have been suggested primarily based on removal of a year or a period and then its re-estimation (Mkhabela et al. 2011; Bolton and Friedl 2013; Kouadio et al. 2014). The current regression-based models were validated in three different ways and the intercepts were set to zero:

(i) leave-one-year-out 
(ii) leave-two-years-out

(iii) leave-half-period-out

For each year of the study period, historical data excluding this year or more were used as training data for the crop production or yield model at each spatial unit. Then, the developed models with one or more years removed were used to estimate the crop production or yield for the missing year.

\subsection{Regression modelling}

Regression models were applied separately for each year at the governorate level. The country consists of eighteen governorates. Regression was applied using decadal composite VIs and annual NPP values (independent variables) to estimate crop production or yield (dependent variable).

For each year of the study period, the fitted regression models used all the historical data excluding one year to estimate the crop production or yield for that missing year. For estimating crop production or yield, and to be comparable with the leave-one-year-out approach, only the data from 2002 to 2010 were used as the NPP product is only available until 2010.

Model accuracy assessment is crucial in scientific research. Here, the performance of the models was assessed by comparing the estimated against the actual crop production or yield. The coefficient of determination and relative error were calculated between the estimated and actual crop production or yield for the held-out-year as follows:

Relative Error $\%=(P P i-A P i) / A P i \times 100$

where $P P i$ is the forecasted production or yield and $A P i$ is the actual crop production or yield.

A schematic diagram illustrating the methodology can be seen in figure (4). 


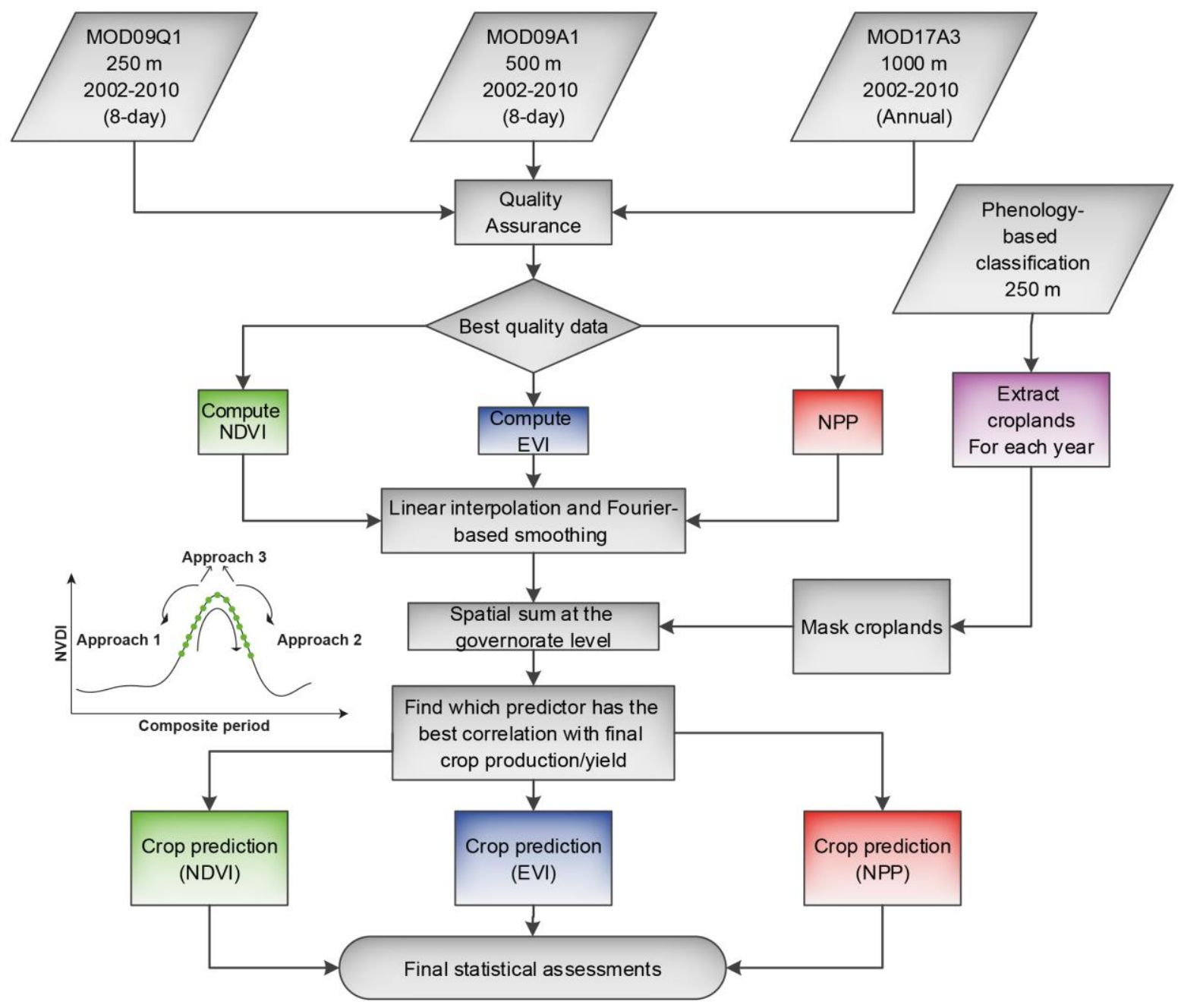

Figure 4. Schematic diagram showing the research methodology adopted in this research.

\section{Results}

\subsection{Estimating phenological parameters for forecasting crop production}

Figure 5 shows the multi-year average coefficients of determination obtained from linear regression utilizing the NDVI and EVI to forecast crop production at 8-day intervals over the growing season for three different approaches from 2002 to 2010 . Figure 5a presents the multi-year average coefficients of determination for the spatial sum of a single variable (original VIs value) from $\operatorname{Max}_{\mathrm{b} 7}$ to $\operatorname{Max}_{\mathrm{a} 7} \mathrm{at}$ the governorate level (approach 1). From figure 5a, it is apparent that the largest coefficient of determination between crop production and the remotely sensed VIs occurs at the maximum, with NDVI producing a slightly larger coefficient of determination than EVI. Figure $5 \mathrm{~b}$ presents the multiyear average coefficients of determination for the integrated spatial sum of the VIs from Max $\mathrm{x}_{\mathrm{b} 7}$ to 
$\operatorname{Max}_{\mathrm{a} 7}$ over the growing season (Approach 2). The largest coefficient of determination was recorded for the period around the maximum over the growing season, with NDVI producing a slightly larger coefficient of determination than EVI. Figure $5 \mathrm{c}$ presents the multi-year average coefficients of determination for the integrated spatial sum of the VIs from the maximum (approach 3). There is a clear trend of increasing coefficients of determination from the beginning of the growing season until the peak of the growing season, and a decrease from the maximum towards the end of the growing season.
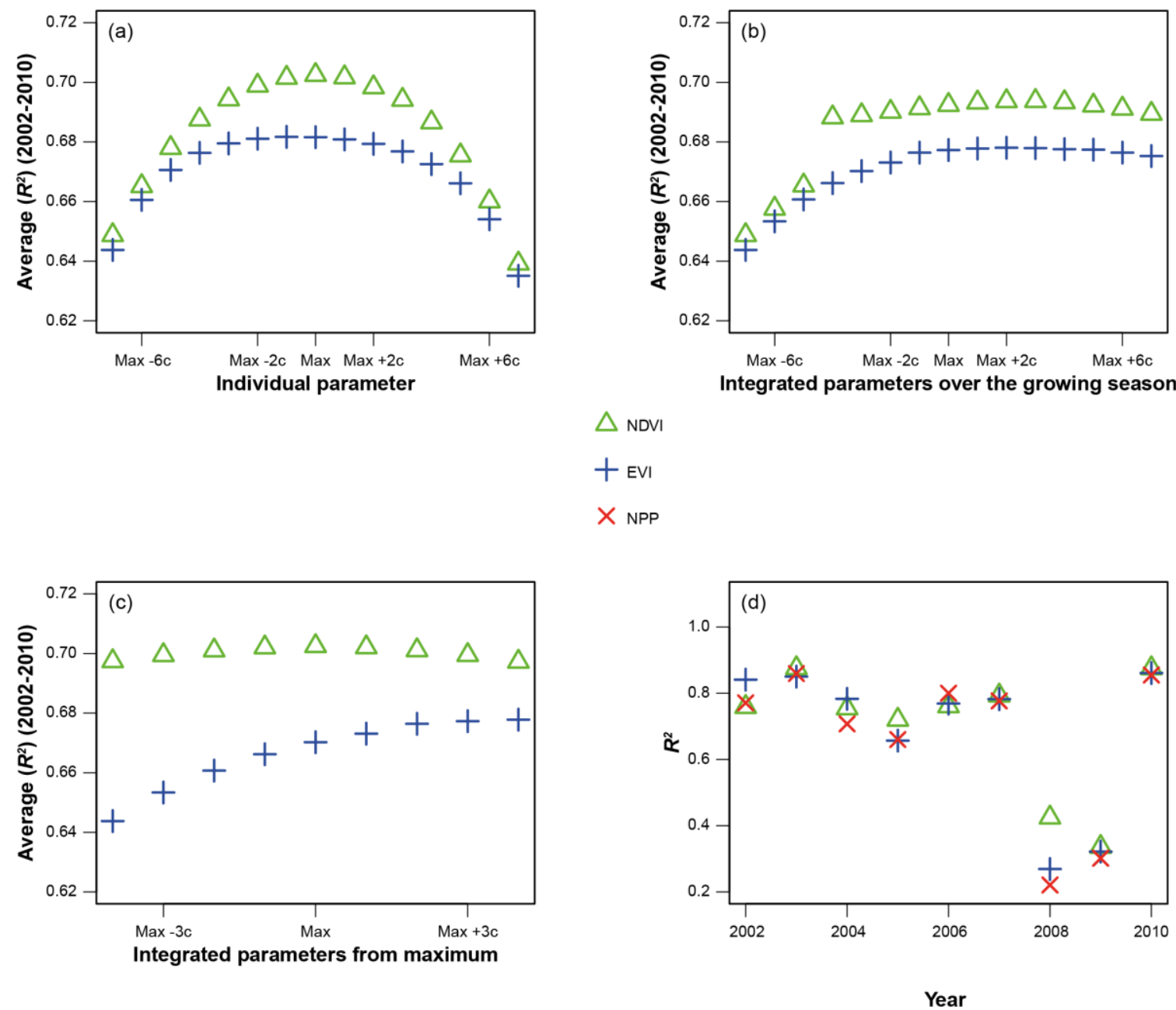

Figure 5. Plots showing the multi-year average coefficient of determination (y-axis) between crop production and VIs for different dates (x-axis) at the governorate level from 2002 to 2010, for three different approaches (a, b, c), and (d) maximum NDVI, maximum EVI and NPP. 
However, as the NPP product is annual-based, it cannot be compared at this stage with VIs (the coefficients of determination for VIs are an average of 8 years for each variable). Therefore, maximum VIs as the best predictor should be compared to the annual NPP value. Figure (5d) depicts the comparison of the coefficients of determination among the maximum VIs (as the best predictor to estimate crop production over the growing season) and annual based NPP over the period. It can be seen from the figure that generally all indices produce relatively large coefficients of determination, with NDVI producing a larger coefficient of determination (Avg. $R^{2}=0.70$ ) than EVI (Avg. $R^{2}=0.68$ ) and NPP (Avg. $R^{2}=0.66$ ). In general, fluctuation through the years can be seen in the figure with the smallest coefficients of determination in 2008 and 2009.

The aim here is not to compare amongst indices: such a comparison would not be fair because of differences in spatial resolution. The current research tended to use the finest spatial resolution for each product to estimate crop production as the region has a small agricultural field size.

Figure (6) shows the coefficients of determination between maximum (a) $500 \mathrm{~m}$ spatial resolution of NDVI and EVI and (b) $1000 \mathrm{~m}$ spatial resolution of NDVI and NPP with crop production, at the governorate level from 2002 to 2010. It can be seen from the figure that after upscaling the NDVI $(250 \mathrm{~m})$ to $500 \mathrm{~m}$ and $1000 \mathrm{~m}$, the sum of maximum NDVI still has a larger coefficient of determination with crop production compared to the EVI and NPP. However, with the decrease of spatial resolution from $250 \mathrm{~m}$ to $500 \mathrm{~m}$ and $1000 \mathrm{~m}$, the average coefficient of determination between the maximum NDVI and crop production at the governorate level decreased from 0.70 to 0.69 . 


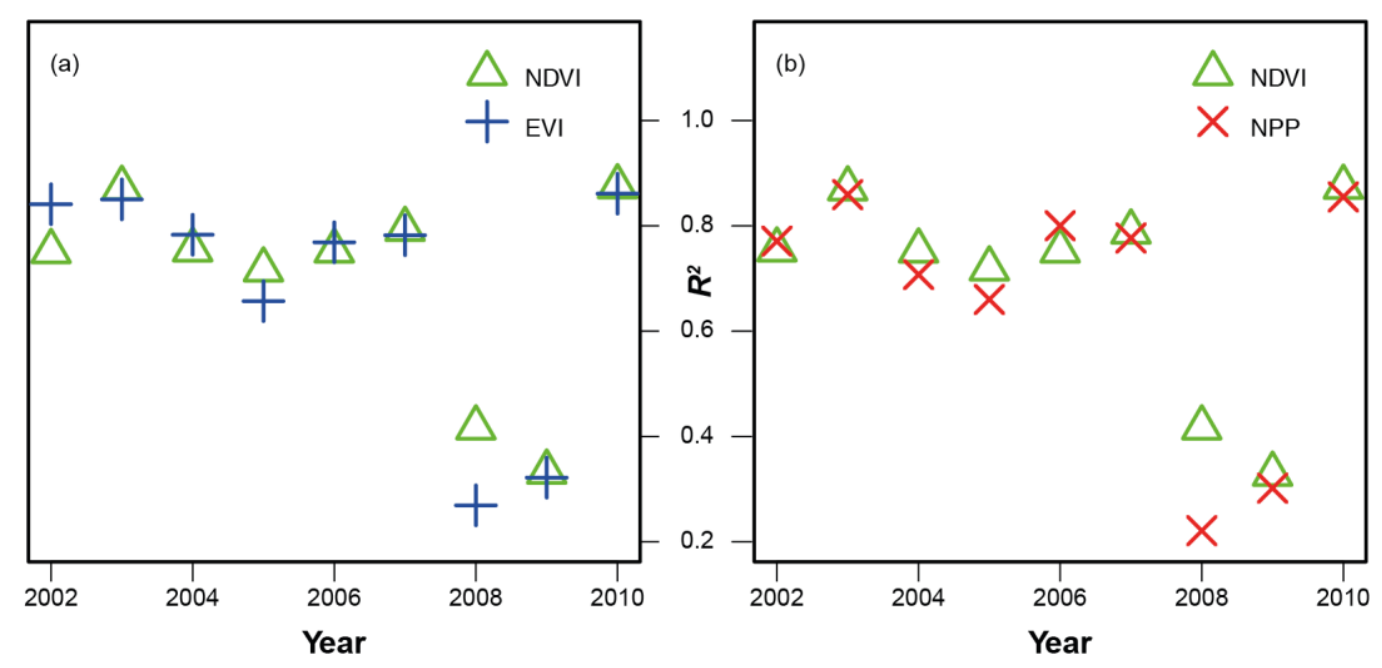

Figure 6. The coefficients of determination between maximum (a) $500 \mathrm{~m}$ spatial resolution of NDVI and EVI and (b) $1000 \mathrm{~m}$ spatial resolution of NDVI and NPP with crop production, at the governorate level from 2002 to 2010 .

Figure (7) depicts the coefficients of determination between ground crop area, estimated crop area (phenology-based classification cropland), maximum spatial sum (NDVI $250 \mathrm{~m}$, EVI $500 \mathrm{~m}$ and NPP $1000 \mathrm{~m}$ ) with crop production, at the governorate level from 2002 to 2010. It can be seen from the figure that the average $R^{2}$ between final crop production and actual crop area was 0.58 and with estimated crop area was 0.63 at the governorate level from 2002 to 2010 . However, using the remotely sensed indices increased the average coefficient of determination to NDVI $=0.70, \mathrm{EVI}=0.68$ and NPP $=0.66$. This indicates that the remotely sensed indices could characterize and forecast crop production more accurately than simple cropping area, which was treated as a null model or benchmark against which to evaluate the proposed approach. 


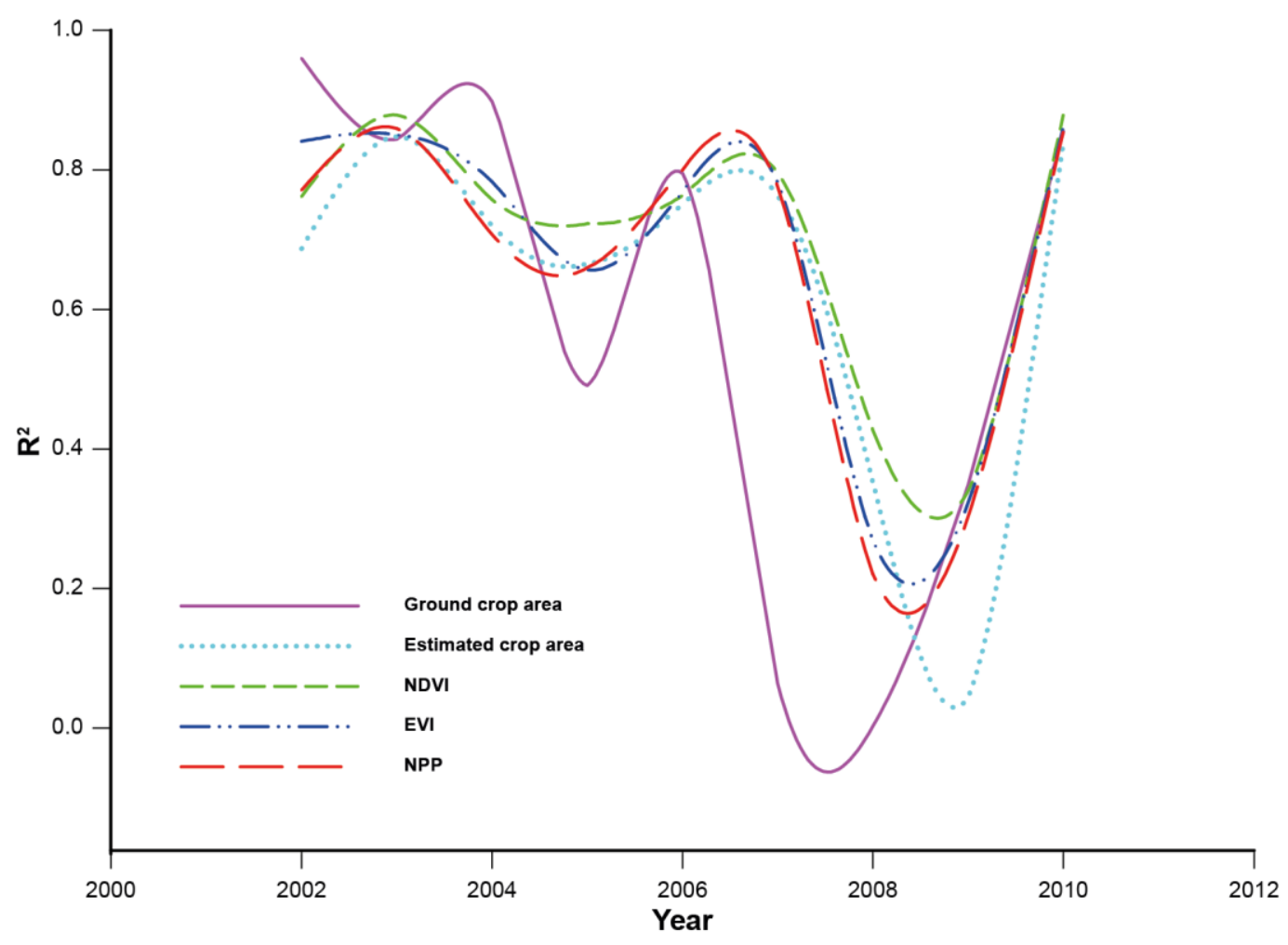

Figure 7. Illustrates the coefficients of determination between ground crop area, estimated crop area (phenology-based classification cropland), maximum spatial sum (NDVI 250 m, EVI $500 \mathrm{~m}$ and NPP $1000 \mathrm{~m}$ ) with crop production, at the governorate level from 2002 to 2010.

\subsection{The extent of cropland area and agricultural field size}

It can be seen from table (2) that the areal extent of cropland per governorate might have an impact on the relationship between the spatial sum of remotely-sensed indices and crop production at the country level. In general, relatively larger coefficients of determination are observed between maximum spatial sum of NDVI $(250 \mathrm{~m})$ and crop production through time at the governorate level with larger crop area. Moreover, due to the relatively small field size with respect to the remote sensing image pixels $(250 \mathrm{~m})$ it was challenging to estimate crop phenology, identify crop types and estimate crop yield accurately. Figure 8 gives some examples of the potential differences in spatial coverage between gridded MODIS $(250 \mathrm{~m})$ pixels and individual agricultural fields in the north-west of Mosul, Ninawa, Iraq. The figure shows clearly that the individual MODIS pixels cover several 
agricultural fields, which may be used to plant different crops. Even if the same crop is planted in several fields covered by a MODIS pixel, within-pixel variability in crop phenology timing may exist as different agricultural management practices may be applied.

Table 2. The percentage of average cropland and percentage of average crop production with the coefficients of determination between maximum spatial sum of NDVI $(250 \mathrm{~m})$ as the best predictor and crop production through time (2002 to 2010) at the governorate level.

\begin{tabular}{cccc}
\hline Governorate & $\begin{array}{c}\text { Average } \\
\text { cropland } \\
(\%)\end{array}$ & $\begin{array}{c}\text { Average crop } \\
\text { Production } \\
(\boldsymbol{\%})\end{array}$ & $\boldsymbol{R}^{\mathbf{2}}$ \\
\hline Anbar & 3.16 & 2.03 & 0.10 \\
Babil & 7.22 & 3.46 & 0.04 \\
Baghdad & 0.28 & 2.54 & 0.54 \\
Basrah & 1.15 & 0.64 & 0.00 \\
Duhok & 5.51 & 5.70 & 0.61 \\
Dyala & 7.11 & 5.40 & 0.19 \\
Erbil & 9.98 & 8.56 & 0.41 \\
Karbala & 0.47 & 0.26 & 0.14 \\
Kirkuk & 8.62 & 8.91 & 0.34 \\
Muthana & 0.55 & 1.06 & 0.00 \\
Mysan & 5.91 & 4.19 & 0.75 \\
Najaf & 1.00 & 2.76 & 0.08 \\
Ninawa & 18.73 & 21.40 & 0.68 \\
Qadsia & 4.56 & 7.91 & 0.33 \\
Salahadin & 4.13 & 3.98 & 0.36 \\
Sulaimani & 11.05 & 7.33 & 0.31 \\
Wasit & 6.42 & 9.76 & 0.26 \\
Ziqar & 4.15 & 4.10 & 0.48 \\
\hline
\end{tabular}



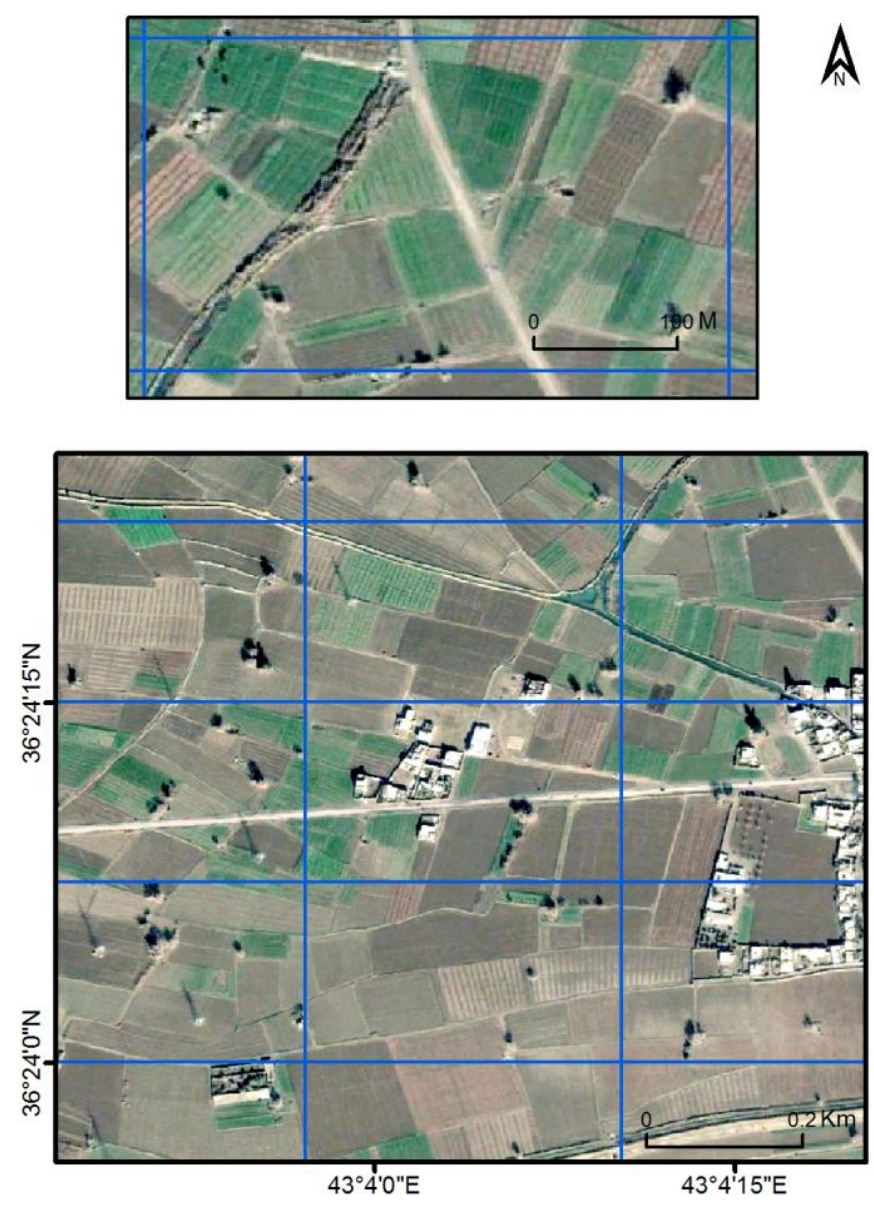

Figure 8. Outline grid of MODIS $250 \mathrm{~m}$ pixels over agricultural land extracted from high spatial Google Earth imagery in north-west Mosul, Ninawa, Iraq.

\subsection{Regression model results and accuracy assessment}

Maximum VIs and annual NPP were used to build the model to forecast crop production. Table 3 provides some summary statistics for the fitted regression models using the leave-one-year-out method to estimate crop production over the region for each year from 2002 to 2010. A large coefficient of determination was found using the leave-one-year-out method for the regression model between the maximum VIs and annual NPP and crop production at the governorate level for each year (Table 3). These coefficients of determination were larger with NDVI compared to EVI and NPP. The regression models for each year in Table 3 were used to estimate crop production at the governorate level. 
Table 3. Linear regression models for estimating wheat and barley production between crop production and the spatially accumulated remotely sensed indices (NDVI, EVI and NPP) at the governorate level (zero intercept). The regression models were trained on eight years of data to forecast crop production in the hold-out year (shown in the left column).

\begin{tabular}{lllllll}
\hline & NDVI & \multicolumn{2}{c}{ EVI } & \multicolumn{2}{c}{ NPP } \\
\hline Year & Model & $R^{2}$ & Model & $R^{2}$ & Model & $R^{2}$ \\
\hline 2002 & $\mathrm{y}=20.296 \mathrm{x}$ & 0.74 & $\mathrm{y}=38.089 \mathrm{x}$ & 0.68 & $\mathrm{y}=568.8 \mathrm{x}$ & 0.68 \\
2003 & $\mathrm{y}=21.568 \mathrm{x}$ & 0.70 & $\mathrm{y}=36.968 \mathrm{x}$ & 0.69 & $\mathrm{y}=604.55 \mathrm{x}$ & 0.67 \\
2004 & $\mathrm{y}=21.96 \mathrm{x}$ & 0.73 & $\mathrm{y}=37.749 \mathrm{x}$ & 0.72 & $\mathrm{y}=607.58 \mathrm{x}$ & 0.70 \\
2005 & $\mathrm{y}=21.33 \mathrm{x}$ & 0.73 & $\mathrm{y}=36.646 \mathrm{x}$ & 0.73 & $\mathrm{y}=596.07 \mathrm{x}$ & 0.71 \\
2006 & $\mathrm{y}=21.067 \mathrm{x}$ & 0.72 & $\mathrm{y}=35.704 \mathrm{x}$ & 0.72 & $\mathrm{y}=582.25 \mathrm{x}$ & 0.68 \\
2007 & $\mathrm{y}=21.481 \mathrm{x}$ & 0.72 & $\mathrm{y}=36.362 \mathrm{x}$ & 0.72 & $\mathrm{y}=594.04 \mathrm{x}$ & 0.70 \\
2008 & $\mathrm{y}=21.074 \mathrm{x}$ & 0.72 & $\mathrm{y}=36.415 \mathrm{x}$ & 0.72 & $\mathrm{y}=586.07 \mathrm{x}$ & 0.70 \\
2009 & $\mathrm{y}=21.15 \mathrm{x}$ & 0.74 & $\mathrm{y}=36.527 \mathrm{x}$ & 0.74 & $\mathrm{y}=588.52 \mathrm{x}$ & 0.72 \\
2010 & $\mathrm{y}=20.542 \mathrm{x}$ & 0.69 & $\mathrm{y}=34.981 \mathrm{x}$ & 0.70 & $\mathrm{y}=569.11 \mathrm{x}$ & 0.67 \\
\hline $\boldsymbol{n = 1 1 4}$ & & & & & &
\end{tabular}

Figure 9 shows the linear relation between forecasted crop production using the developed regressionbased models in Table 3 and official estimates of crop production at the governorate level from 2002 to 2010. It can be seen from the figure that the data are linearly correlated. Table 4 presents the summary statistics for the forecasted and actual crop production for each year over the region. In general, it can be seen from the data in Table 4 that $R^{2}$ is large, but there is variation amongst years and amongst VIs. Generally, large coefficients of determination were observed for each year for all input indices employed for the modelling; $R^{2}$ values ranged from 0.65 to 0.88 . However, the smallest coefficients of determination were recorded for 2008 and 2009 (drought years). The largest coefficient of determination was obtained for NDVI (Avg $\left.R^{2}=0.70\right)$ followed by EVI and NPP (Avg $R^{2}=0.68$ and Avg $R^{2}=0.66$ ). As table 4 shows, there is a clear increase in relative error for forecasting crop production with a decreasing spatial resolution (NDVI $250 \mathrm{~m}$, EVI $500 \mathrm{~m}$ and NPP $1000 \mathrm{~m}$ ). When comparing winter wheat and barley production forecasts made using NDVI against official statistics, the relative error ranged from -20 to $20 \%$. Meanwhile for estimated production using EVI, the relative error ranged from -45 to $28 \%$ and it ranged from -48 to $22 \%$ for estimating crop production using 
NPP. In general, the drought years (2008 and 2009) were found to have the largest relative error over the period.

Table 4. Coefficients of determination and the relative error between actual and forecasted crop production for all models.

\begin{tabular}{|c|c|c|c|c|c|c|c|c|c|c|c|c|}
\hline & NDVI & & & & EVI & & & & NPP & & & \\
\hline Year & $\begin{array}{c}\text { Estimated } \\
\text { MT }\end{array}$ & $\begin{array}{l}\text { Actual } \\
\text { MT }\end{array}$ & $R^{2}$ & $\begin{array}{c}\text { Error } \\
\%\end{array}$ & $\begin{array}{c}\text { Estimated } \\
\text { MT }\end{array}$ & $\begin{array}{l}\text { Actual } \\
\text { MT }\end{array}$ & $R^{2}$ & $\begin{array}{c}\text { Error } \\
\%\end{array}$ & $\begin{array}{c}\text { Estimated } \\
\text { MT }\end{array}$ & $\begin{array}{l}\text { Actual } \\
\text { MT }\end{array}$ & $R^{2}$ & $\begin{array}{c}\text { Error } \\
\%\end{array}$ \\
\hline 2002 & 3.86 & 4.33 & 0.76 & -10 & 5.44 & 4.33 & 0.84 & +26 & 3.74 & 4.33 & 0.77 & -14 \\
\hline 2003 & 4.22 & 3.83 & 0.87 & +10 & 4.03 & 3.83 & 0.85 & +5 & 4.13 & 3.83 & 0.85 & +8 \\
\hline 2004 & 3.87 & 3.23 & 0.75 & +20 & 4.14 & 3.23 & 0.78 & +28 & 3.93 & 3.23 & 0.70 & +22 \\
\hline 2005 & 3.72 & 3.79 & 0.72 & -2 & 3.11 & 3.79 & 0.65 & -18 & 3.38 & 3.79 & 0.66 & -11 \\
\hline 2006 & 3.97 & 3.92 & 0.76 & +1 & 2.92 & 3.92 & 0.76 & -26 & 3.45 & 3.92 & 0.80 & -12 \\
\hline 2007 & 4.09 & 4.21 & 0.79 & -3 & 3.31 & 4.21 & 0.78 & -21 & 3.57 & 4.21 & 0.77 & -15 \\
\hline 2008 & 1.59 & 1.94 & 0.42 & -18 & 1.06 & 1.94 & 0.26 & -45 & 1.01 & 1.94 & 0.22 & -48 \\
\hline 2009 & 2.50 & 3.04 & 0.33 & -18 & 2.04 & 3.04 & 0.32 & -33 & 2.08 & 3.04 & 0.30 & -32 \\
\hline 2010 & 4.02 & 5.00 & 0.87 & -19 & 3.38 & 5.00 & 0.86 & -32 & 3.69 & 5.00 & 0.85 & -26 \\
\hline
\end{tabular}

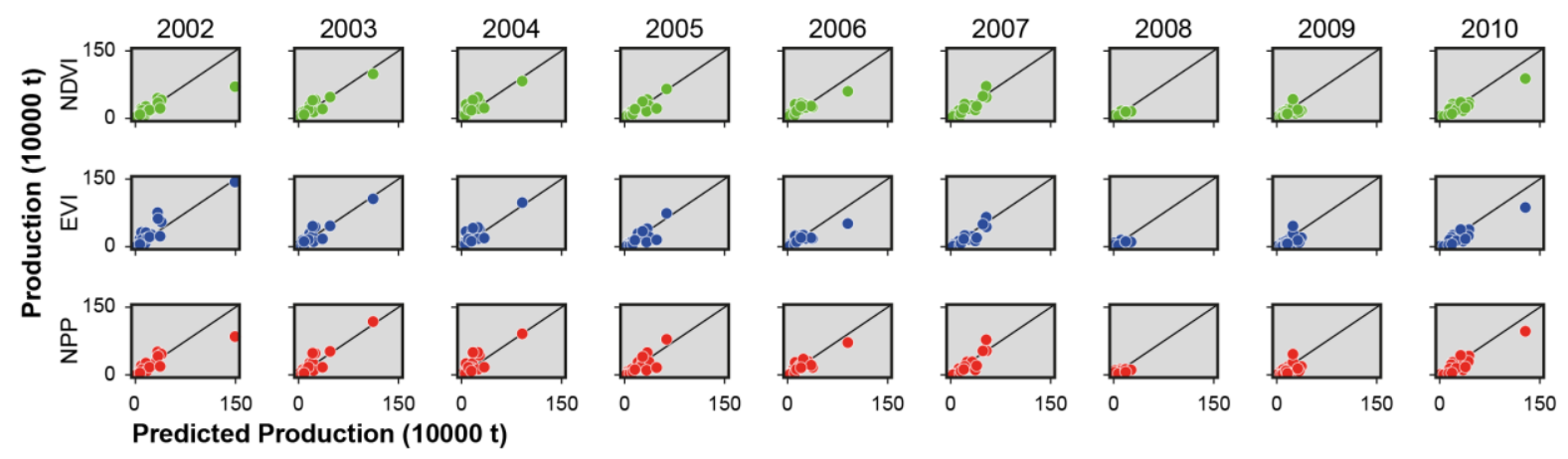

Figure 9. Scatterplots of official estimates of production against remotely sensed forecasts of production made using the leave-one-year-out approach, and using (a to i) NDVI from 2002 to 2010; ( $\mathrm{j}$ to r) EVI from 2002 to 2010; (s to ab) NPP from 2002 to 2010 at the governorate level. 1:1 line shown for comparison. 


\subsection{Crop yield estimation}

The same methodology as presented in section 2.6 was used to forecast crop yield over the region. However, based on the available data, we found that crop yield could not be estimated satisfactorily at the governorate level in Iraq. The results of the regression analysis for two examples are shown in Figure 10. Figure 10a shows the coefficient of determination between crop yield and the average maximum NDVI for all governorates within each year. Very small coefficients of determination were found for each year, except for 2002. In the second example, the coefficients of determination between crop yield and the average maximum NDVI during the period for each governorate are very small (Figure 10b). However, a slightly larger positive coefficient of determination was observed for the Kurdistan governorates (Sulaimani, Erbil and Duhok).
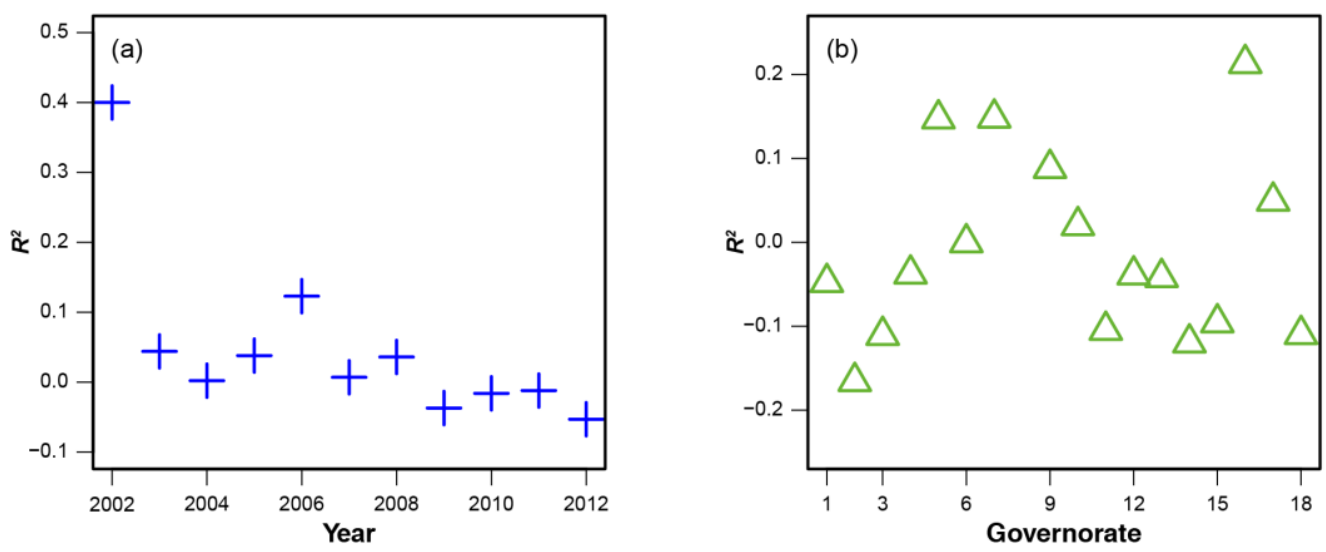

Figure 10. (a) the coefficients of determination between crop yield and the average maximum NDVI for all governorates within each year, (b) the coefficients of determination between crop yield and the average maximum NDVI during the period for each governorate ((1) Anbar, (2) Babil, (3) Baghdad, (4) Basrah, (5) Duhok, (6) Dyala, (7) Erbil, (8) Karbala, (9) Kirkuk, (10) Muthana, (11) Mysan, (12) Najaf, (13) Ninawa, (14) Qadsia, (15) Salahadin, (16) Sulaimani, (17) Wasit and (18) Ziqar)).

\section{Discussion}


As Iraq has experienced, and continues to experience, various natural and anthropogenic impacts on crop production, it remains food insecure. Therefore, quantifying its regional crop production in advance could help policy-makers, scientists and decision-makers to improve agricultural management and food security under a variety of environmental conditions. The model developed here for Iraq, as an example of an arid and semi-arid region, should be extended and tested for other similar regions.

Although this research tested several methodological approaches, it was not possible to forecast crop yield at the governorate level over Iraq. There are several possible explanations for this result. It has been demonstrated that the official Iraqi government statistics are likely to be unreliable (USDA FAS, 2008b). It has also been reported that international statistics data for Iraq for production, yield and harvested area are often "unofficial" or estimated figures, or other sources have been used to estimate uncovered or missing data (FAO 2012). This was further evident from the fact that the coefficient of determination between the average maximum NDVI and crop yield for 2002 was much larger compared to the rest of the period (Figure 10a). This result could be explained by the fact that besides more regional instability, at that time the Food and Agriculture Organization (FAO) conducted a more accurate ground survey over the region. In addition, as the Kurdistan region is more stable in terms of security compared to the rest of Iraq during the last decade, slightly larger coefficients of determination were found for Slaimani, Erbil and Duhok (Figure 10b). However, double counting in the agricultural statistics at the governorate level for the disputed areas between Kurdish Government and Central Government has led to poor ground data quality and low coefficients of determination. In addition, for many areas in Iraq access was restricted by the local authority due to security issues. Thus, for such areas the ground survey was replaced by estimation. Furthermore, there might be some impacts of environmental factors as the Kurdish governorates are mostly rain-fed areas compared to rest of Iraq which are mainly irrigated areas. The impact of natural extreme events and regional instability might have affected irrigation infrastructures crucial to agricultural production and, thus, the estimation of crop production in these areas may not be reliable. Another possible explanation for the lack of correlation is the coarse spatial resolution of the data used in this study compared to the small agricultural field size in Iraq. A coarse spatial resolution could prevent capture of the phenology 
of a pure crop in some areas since the region has small agricultural field sizes. Another source of uncertainty might be related to the crop map used for the current research, which was not able to separate wheat and barley due to their similar crop calendars and phenological responses in the region (Qader et al. 2015). Due, in part, to greater variability of their yields from one year to the next, yield forecasting is more challenging for both together. Another possible explanation for this could be the large inter-annual variation in terms of croplands at the governorate level as the traditional biennial fallow system is practiced widely in the region to recharge the depleted soil and decrease the impact of pests and disease particularly in the north (FAO 2011; Schnepf 2004).

Winter wheat and barley production were highly and linearly correlated with the spatial accumulated NDVI and EVI obtained during maximum green canopy cover at the governorate level in Iraq, compared to the other variables. Therefore, the seasonal maximum NDVI and EVI were selected as this enabled timely forecasting of crop production around a month and half prior to harvest. These results are in line with previous studies that found similar results with either crop production or yield (Becker-Reshef et al. 2010; Doraiswamy and Cook 1995; Mahey et al. 1993; Tucker 1980). In terms of comparison amongst the employed indices, it is apparent from statistical evaluation of the results that NDVI could have an advantage relative to the EVI and NPP for forecasting crop production in the region using the leave-one-year-out approach. A possible explanation for this might be that MODISNDVI has a finer spatial resolution (250 m) than MODIS-EVI (500 m) and MODIS-NPP (1000 m). This might make the NDVI data more sensitive to annual variation and capture the detailed phenological characteristics of cropland cover type. In general, a large relative error was obtained for forecasting crop production for 2008 and 2009 when the region experienced a severe drought (Schnepf 2004; Griffin and Kunz 2009). This is potentially a limitation of the remotely sensed-based regression model, and this has been pointed out in several studies where it has not been possible to capture the impact of extreme events (Kouadio et al. 2014; Becker-Reshef et al. 2010). In addition, in normal years such as 2002-to-2007 and 2010, the correlation between crop production and the remote sensing indices is relatively large as there is crop failure is less prevalent resulting in similar crop planted and harvested areas. However, during drought years, the planted area cannot be estimated well 
as there are many cases of crop failure. Therefore, crop production may be over-estimated. This could lead to the differences in $R^{2}$ between normal years and drought years.

There is room for further progress in forecasting crop production and yield at the governorate level in Iraq. To increase the quality of data, an accurate and intensive ground survey with a robust experimental design is needed to obtain accurate data on crop yield. It is also important to note that low intensity agriculture and the widely practiced traditional biennial fallow system is difficult to detect at the $250 \mathrm{~m}$ spatial resolution of MODIS. The land cover classification map used in this study also was unable to separate wheat and barley over the region. Identification of winter wheat and barley area is a vital component to modelling and forecasting crop production and yield using remotely sensed data. For example, a significant increase in the accuracy of crop yield forecasts was observed while a crop map was applied to mask NDVI values as an input to a crop yield model (Maselli et al. 2000; Genovese at al. 2001; Ren et al. 2008). In addition, the low accuracy may be related to the high sensitivity of photosynthetic activity to environmental factors. This might be improved by using VIs sensitive to chlorophyll content as they have less tendency to saturate at high biomass compared to other VIs sensitive to leaf area index (LAI) (Zhang and Liu 2014). As the region has an extreme climatic condition and crop production and yield vary considerably with the amount of rainfall, further studies, which consider climatic variables, will need to be undertaken.

As stated above, Iraq remains food insecure due to a variety of environmental and social challenges. Quantifying its regional crop production in advance, within-year could help policy-makers, scientists and decision-makers to improve agricultural management and food security. The remote sensingbased model developed here for Iraq, as an example of the large number of countries in arid and semiarid regions, should be extended and tested for other countries.

\section{Conclusion}

Due to various natural and anthropogenic factors affecting agricultural production, many arid and semi-arid regions are food insecure. This risk can be reduced if policy-makers have early forecasts of production. The main aim was to evaluate the potential of MODIS-derived measures of greenness and 
productivity, and information related to the phenology of crops, to estimate crop production and yield in arid and semi-arid regions like Iraq.

This research has shown that crop production was most correlated with the maximum VIs at the governorate level compared to other MODIS-derived indicators related to the timing of crop phenology. It also demonstrated that remotely sensed indices could forecast crop production more accurately than simple cropping area. In addition, the model produced a reasonable range of relative errors between forecasted crop production and official statistics.

Food insecurity in arid and semi-arid regions is crucial topic due to the vulnerability of such regions, and while the models presented here exhibited limited success in forecasting crop yield, they do demonstrate benefits over simple crop area-based models for forecasting crop production. Moreover, the greatest limitation on the observed accuracy lies with the lack of accurate data for calibration and not necessarily with the predictive model itself. It is, thus, anticipated that the value of these models in the context of food insecurity in highly vulnerable arid and semi-arid regions will be greater than the accuracy statistics observed here suggest. Moreover, this paper demonstrates the need for more accurate ground data in arid and semi-arid regions to drive these types of models.

\section{Acknowledgements}

This work was supported by the Ministry of Higher Education (Kurdistan Regional Government (KRG)). The authors gratefully acknowledge the NASA Land Processes Distributed Active Archive Center (LP DAAC) for providing free access to the MODIS images.

\section{References}

Abi-Ghanem, R., Carpenter-Boggs, L., Koenig, R., Pannkuk, C., Pan, W., \& Parker, R. (2009). Extension Education for Dryland Cropping Systems in Iraq. Journal of Natural Resources and Life Sciences Education, 38, 133-139. doi: 10.4195/jnrlse.2009.0001 
Andarzian, B., Bakhshandeh, A. M., Bannayan, M., Emam, Y., Fathi, G., \& Saeed, K. A. (2008). WheatPot: A simple model for spring wheat yield potential using monthly weather data. Biosystems Engineering, 99(4), 487-495. doi: 10.1016/j.biosystemseng.2007.12.008

Balaghi, R., Tychon, B., Eerens, H., \& Jlibene, M. (2008). Empirical regression models using NDVI, rainfall and temperature data for the early prediction of wheat grain yields in Morocco. International Journal of Applied Earth Observation and Geoinformation, 10(4), 438-452. doi: 10.1016/j.jag.2006.12.001

Barakat H. N. (2009). Arid lands: challenges and hopes. Earth system: history and natural variabilityVol. III. EOLSS publishers.

Becker-Reshef, I., Justice, C., Sullivan, M., Vermote, E., Tucker, C., Anyamba, A., Doorn, B. (2010). Monitoring Global Croplands with Coarse Resolution Earth Observations: The Global Agriculture Monitoring (GLAM) Project. Remote Sensing, 2(6), 1589-1609. doi: $10.3390 / \mathrm{rs} 2061589$

Benedetti, R., \& Rossini, P. (1993). On the use of NDVI profiles as a tool for agricultural statistics-the case-study of wheat yield estimate and forecast in Emilia-Romagna. Remote Sensing of Environment, 45(3), 311-326. doi: 10.1016/0034-4257(93)90113-c

Boken, V. K., \& Shaykewich, C. F. (2002). Improving an operational wheat yield model using phenological phase-based Normalized Difference Vegetation Index. International Journal of Remote Sensing, 23(20), 4155-4168. doi: 10.1080/01431160110075839

Bolton, D. K., \& Friedl, M. A. (2013). Forecasting crop yield using remotely sensed vegetation indices and crop phenology metrics. Agricultural and Forest Meteorology, 173, 74-84. doi: 10.1016/j.agrformet.2013.01.007

Brisson, N., Mary, B., Ripoche, D., Jeuffroy, M. H., Ruget, F., Nicoullaud, B., Delecolle, R. (1998). STICS: a generic model for the simulation of crops and their water and nitrogen balances. I. Theory and parameterization applied to wheat and corn. Agronomie, 18(5-6), 311-346. doi: 10.1051/agro:19980501 
Central Organization for Statistics and Information Technology (COSIT) in Iraq, 2011. Area and Number of Holdings by Land Use on National Level and Governorates According to the Agricultural Censuses of the Year 2001. http://www.cosit.gov.iq/en/ (accessed 16.01.15).

Dash, J., Jeganathan, C., \& Atkinson, P. M. (2010). The use of MERIS Terrestrial Chlorophyll Index to study spatio-temporal variation in vegetation phenology over India. Remote Sensing of Environment, 114(7), 1388-1402. doi: 10.1016/j.rse.2010.01.021.

Dadhwall, V. K., \& Ray, S. S. (2000). Crop assessment using remote sensing -Part II: Crop condition and yield assessment. Indian Journal of Agriculture Economy, 2 (1947-4, 55-67.

d'Amour, C. B., Wenz, L., Kalkuhl, M., Steckel, J. C., \& Creutzig, F. (2016). Teleconnected food supply shocks. Environmental Research Letters, 11(3). doi:10.1088/1748-9326/11/3/035007.

De Wit, A. J. W., \& Boogaard, H. L. (2001). Monitoring of crop development and crop model optimisation using NOAA-AVHRR; towards an integrated satellite and model-based crop monitoring system in the European context. (Delft, BCRS, NRSP-2 Rep. 00-12).

Doraiswamy, P. C., \& Cook, P. W. (1995). Spring wheat yield assessment using NOAA AVHRR data. Canadian Journal of Remote Sensing, 21, 43-51.

Doraiswamy, P. C., Hatfield, J. L., Jackson, T. J., Akhmedov, B., Prueger, J., \& Stern, A. (2004). Crop condition and yield simulations using Landsat and MODIS. Remote Sensing of Environment, 92(4), 548-559. doi: 10.1016/j.rse.2004.05.017

Doraiswamy, P. C., Moulin, S., Cook, P. W., \& Stern, A. (2003). Crop yield assessment from remote sensing. Photogrammetric Engineering and Remote Sensing, 69(6), 665-674.

Doraiswamy, P. C., Sinclair, T. R., Hollinger, S., Akhmedov, B., Stern, A., \& Prueger, J. (2005). Application of MODIS derived parameters for regional crop yield assessment. Remote Sensing of Environment, 97(2), 192-202. doi: 10.1016/j.rse.2005.03.015

Esquerdo, J. C. D. M., Zullo Junior, J., \& Antunes, J. F. G. (2011). Use of NDVI/AVHRR time-series profiles for soybean crop monitoring in Brazil. International Journal of Remote Sensing, 32(13), 3711-3727. doi: 10.1080/01431161003764112. 
Fellmann T, Hélaine S and Nekhay O 2014. Harvest failures, temporary export restrictions and global food security: the example of limited grain exports from Russia, Ukraine and Kazakhstan Food Secur. 6 727-42.

Food Agriculture Organization of the United Nations (FAO) 2011. Country Pasture/Forage Resource Profiles. Rome, Italy. http://www.fao.org/ag/agp/AGPC/doc/Counprof/Iraq/Iraq.html (accessed 23.10.13).

Food Agriculture Organization of the United Nations (FAO) 2012. Iraq Agriculture sector note. Rome, Italy. http://www.fao.org/docrep/017/i2877e/i2877e.pdf (accessed 15.04.17).

Food Agriculture Organization of the United Nations Aquastat (FAO aquastat). 2013. Food and agriculture organization of the United Nations statistics division. http://faostat3.fao.org/download/Q/QC/E (accessed 15.07.15).

Food Agriculture Organization of the United Nations Aquastat (FAO) 2008. Iraq, Geography, Climate and Population. http://www.fao.org/nr/water/aquastat/main/index.stm (accessed 16.08.13).

Food and Agricultural Organization (FAO) (2012). Crop Production Statistics for Iraq. http://faostat.fao.org/ (accessed 06.01.13).

Food and Agriculture Organization of the United Nation (FAO) (2003a). The State of Food and Agriculture in 32nd Session of the FAO Conference Rome, Italy.

Food and Agriculture Organization of the United Nation (FAO) (2003b). The State of Food Insecurity in the World. Monitoring progress towards the World Food Summit and Millennium Development Goals, Food and Agriculture Organization of the United Nations, Rome, Italy.

FAO, IFAD and WFP. 2015. The State of Food Insecurity in the World 2015. Meeting the 2015 international hunger targets: taking stock of uneven progress. Rome, FAO.

Genovese, G., Vignolles, C., Negre, T., \& Passera, G. (2001). A methodology for a combined use of normalised difference vegetation index and CORINE land cover data for crop yield monitoring and forecasting. A case study on Spain. Agronomie, 21(1), 91-111.

Gibson, G. R., Campbell, J. B., \& Wynne, R. H. (2012). Three Decades of War and Food Insecurity in Iraq. Photogrammetric Engineering and Remote Sensing, 78(8), 885-895. 
Griffin, S. and E. Kunz (2009). Data fusion and integration of high and medium resolution imagery for crop analysis. ASPRS 2009 Annual Conference. A. S. f. P. a. R. Sensing. Baltimore, Maryland.

Groten, S. M. E. (1993). NDVI - monitoring and early yield assessment of Burkina-Faso. International Journal of Remote Sensing, 14(8), 1495-1515.

Haile, M. (2005). Weather patterns, food security and humanitarian response in sub-Saharan Africa. Philosophical Transactions of the Royal Society B-Biological Sciences, 360(1463), 21692182. doi: $10.1098 /$ rstb.2005.1746

Hamar, D., Ferencz, C., Lichtenberger, J., Tarcsai, G., \& FerenczArkos, I. (1996). Yield estimation for corn and wheat in the Hungarian great plain using Landsat MSS data. International Journal of Remote Sensing, 17(9), 1689-1699.

Hatfield, J. L., \& Prueger, J. H. (2010). Value of Using Different Vegetative Indices to Quantify Agricultural Crop Characteristics at Different Growth Stages under Varying Management Practices. Remote Sensing, 2(2), 562-578. doi: 10.3390/rs2020562

Huang, J., Wang, X., Li, X., Tian, H., \& Pan, Z. (2013). Remotely Sensed Rice Yield Prediction Using Multi-Temporal NDVI Data Derived from NOAA's-AVHRR. Plos One, 8(8). doi: 10.1371/journal.pone.0070816.

Huete, A. R., Liu, H. Q., Batchily, K., \& vanLeeuwen, W. (1997). A comparison of vegetation indices global set of TM images for EOS-MODIS. Remote Sensing of Environment, 59(3), 440-451. doi: 10.1016/s0034-4257(96)00112-5

Jiang, Z. Y., Huete, A. R., Didan, K., \& Miura, T. (2008). Development of a two-band enhanced vegetation index without a blue band. Remote Sensing of Environment, 112(10), 3833-3845. doi: 10.1016/j.rse.2008.06.006

Jianqiang, R., Su, L., Zhongxin, C., Qingbo, Z., \& Huajun, T. (2008). Regional yield prediction for winter wheat based on crop biomass estimation using multi-source data. 2007 IEEE International Geoscience and Remote Sensing Symposium, IGARSS 2007, 805-808. 
Kastens, J. H., Kastens, T. L., Kastens, D. L. A., Price, K. P., Martinko, E. A., \& Lee, R. Y. (2005). Image masking for crop yield forecasting using AVHRR NDVI time series imagery. Remote Sensing of Environment, 99(3), 341-356. doi: 10.1016/j.rse.2005.09.010

Kogan, F., Salazar, L., \& Roytman, L. (2012). Forecasting crop production using satellite-based vegetation health indices in Kansas, USA. International Journal of Remote Sensing, 33(9), 2798-2814. doi: 10.1080/01431161.2011.621464

Kogan, F., Kussul, N., Adamenko, T., Skakun, S., Kravchenko, O., Kryvobok, O., Lavrenyuk, A. (2013). Winter wheat yield forecasting in Ukraine based on Earth observation, meteorological data and biophysical models. International Journal of Applied Earth Observation and Geoinformation, 23, 192-203. doi: 10.1016/j.jag.2013.01.002

Kouadio, L., Newlands, N. K., Davidson, A., Zhang, Y. S., \& Chipanshi, A. (2014). Assessing the Performance of MODIS NDVI and EVI for Seasonal Crop Yield Forecasting at the Ecodistrict Scale. Remote Sensing, 6(10), 10193-10214. doi: 10.3390/rs61010193

Labus, M. P., Nielsen, G. A., Lawrence, R. L., Engel, R., \& Long, D. S. (2002). Wheat yield estimates using multi-temporal NDVI satellite imagery. International Journal of Remote Sensing, 23(20), 4169-4180. doi: 10.1080/01431160110107653

Liu, W. T., \& Kogan, F. (2002). Monitoring Brazilian soybean production using NOAA/AVHRR based vegetation condition indices. International Journal of Remote Sensing, 23(6), 11611179. doi: $10.1080 / 01431160110076126$

Lobell, D. B., Sibley, A., \& Ivan Ortiz-Monasterio, J. (2012). Extreme heat effects on wheat senescence in India. Nature Climate Change, 2(3), 186-189. doi: 10.1038/nclimate1356

Lobell, D. B., Asner, G. P., Ortiz-Monasterio, J. I., \& Benning, T. L. (2003). Remote sensing of regional crop production in the Yaqui Valley, Mexico: estimates and uncertainties. Agriculture Ecosystems \& Environment, 94(2), 205-220. doi: 10.1016/s0167-8809(02)00021$\mathrm{x}$

Macdonald, R. B., \& Hall, F. G. (1980). Global crop monitoring. Science, 208(4445), 670-679. doi: $10.1126 /$ science. 208.4445 .670 
Mahey, R. K., Singh, R., Sidhu, S. S., Narang, R. S., Dadhwal, V. K., Parihar, J. S., \& Sharma, A. K. (1993). Preharvest state-level wheat acreage estimation using IRS-IA LISS-I data in Punjab (India). International Journal of Remote Sensing, 14(6), 1099-1106.

Maselli, F., Romanelli, S., Bottai, L., \& Maracchi, G. (2000). Processing of GAC NDVI data for yield forecasting in the Sahelian region. International Journal of Remote Sensing, 21(18), 35093523. doi: 10.1080/014311600750037525

Mellor, J. W. (1972). Accelerated Growth in Agricultural Production and Intersectional Transfer of Resources: epartment of Agricultural Economics Cornell University, No 34.

Meng, W., Fu-Lu, T., \& Wen-Jiao, S. (2014). Corn Yield Forecasting in Northeast China Using Remotely Sensed Spectral Indices and Crop Phenology Metrics. Journal of Integrative Agriculture, 13(7), 1538-1545. doi: 10.1016/s2095-3119(14)60817-0

Millennium Ecosystem Assessment, 2005. Ecosystems and Human Well-being: Biodiversity Synthesis. World Resources Institute, Washington, DC.

Mkhabela, M. S., Bullock, P., Raj, S., Wang, S., \& Yang, Y. (2011). Crop yield forecasting on the Canadian Prairies using MODIS NDVI data. Agricultural and Forest Meteorology, 151(3), 385-393. doi: 10.1016/j.agrformet.2010.11.012

Mkhabela, M. S., Mkhabela, M. S., \& Mashinini, N. N. (2005). Early maize yield forecasting in the four agro-ecological regions of Swaziland using NDVI data derived from NOAAs-AVHRR. Agricultural and Forest Meteorology, 129(1-2), 1-9. doi: 10.1016/j.agrformet.2004.12.006

Moriondo, M., Maselli, F., \& Bindi, M. (2007). A simple model of regional wheat yield based on NDVI data. European Journal of Agronomy, 26(3), 266-274. doi: 10.1016/j.eja.2006.10.007

NASA, Land Processes Distributed Active Archive Centre (LP DAAC). MODIS land surface reflectance (MOD09Q1) and MODIS land cover type (MCD12Q1) 2013. (https://lpdaac.usgs.gov/data access).

Paul, R. K., Prajneshu, \& Ghosh, H. (2013). Statistical modelling for forecasting of wheat yield based on weather variables. Indian Journal of Agricultural Sciences, 83(2), 180-183. 
Qader, S. H., Atkinson, P. M., \& Dash, J. (2015). Spatiotemporal variation in the terrestrial vegetation phenology of Iraq and its relation with elevation. International Journal of Applied Earth Observation and Geoinformation, 41, 107-117. doi: 10.1016/j.jag.2015.04.021

Qader, S. H., Dash, J., Atkinson, P. M., \& Rodriguez-Galiano, V. (2016). Classification of Vegetation Type in Iraq Using Satellite-Based Phenological Parameters. Ieee Journal of Selected Topics in Applied Earth Observations and Remote Sensing, 9(1), 414-424. doi: $10.1109 /$ jstars.2015.2508639

Ren, J. Q., Chen, Z. X., Zhou, Q. B., \& Tang, H. J. (2008). Regional yield estimation for winter wheat with MODIS-NDVI data in Shandong, China. International Journal of Applied Earth Observation and Geoinformation, 10(4), 403-413. doi: 10.1016/j.jag.2007.11.003

Reynolds, C. A., Yitayew, M., Slack, D. C., Hutchinson, C. F., Huete, A., \& Petersen, M. S. (2000). Estimating crop yields and production by integrating the FAO Crop specific Water Balance model with real-time satellite data and ground-based ancillary data. International Journal of Remote Sensing, 21(18), 3487-3508. doi: 10.1080/014311600750037516

Rocha, A. V., \& Shaver, G. R. (2009). Advantages of a two band EVI calculated from solar and photosynthetically active radiation fluxes. Agricultural and Forest Meteorology, 149(9), 1560-1563. doi: 10.1016/j.agrformet.2009.03.016

Rojas, O. (2007). Operational maize yield model development and validation based on remote sensing and agro-meteorological data in Kenya. International Journal of Remote Sensing, 28(17), 3775-3793. doi: 10.1080/01431160601075608

Schnepf, R., 2004. Iraq Agriculture and Food Supply: Background and Issues, Congressional Research Service. The Library of Congress, Washington D.C, 9 and 10 pp.

Tucker, C. J., Holben, B. N., Elgin, J. H., \& McMurtrey, J. E. (1980). RELATIONSHIP OF SPECTRAL DATA TO GRAIN-YIELD VARIATION. Photogrammetric Engineering and Remote Sensing, 46(5), 657-666.

United States Department of Agriculture Foreign Agricultural Service (USDA FAS) (2008a). Drought reduces 2008/09 winter grain production, USDA-FAS, Office of Global Analysis. http://www.pecad.fas.usda.gov/highlights/2008/05/iraq_may2008.htm (accessed 16.11.14). 
United States Department of Agriculture Foreign Agricultural Service (USDA FAS) (2008b). MIDDLE EAST \& CENTRAL ASIA: Continued Drought in 2009/10 Threatens Greater Food Grain Shortages. Commodity intelligent report. http://www.pecad.fas.usda.gov/highlights/2008/09/mideast_cenasia_drought/ (accessed 20.01.15).

Van Evert, F. K., \& Campbell, G. S. (1994). CROPSYST - A Collection of object-oriented simulation-models of agricultural systems. Agronomy Journal, 86(2), 325-331.

Vandiepen, C. A., Wolf, J., Vankeulen, H., \& Rappoldt, C. (1989). WOFOST - A Simulation-model of crop production. Soil Use and Management, 5(1), 16-24.

Wall, L., Larocque, D., \& Leger, P.-M. (2008). The early explanatory power of NDVI in crop yield modelling. International Journal of Remote Sensing, 29(8), 2211-2225. doi: $10.1080 / 01431160701395252$

Wheeler, T., \& von Braun, J. (2013). Climate Change Impacts on Global Food Security. Science, 341(6145), 508-513. doi: 10.1126/science.1239402

World Food Programme (WFP) (2011). Food Insecurity and Violent Conflict: Causes, Consequences, and Addressing the Challenges. Brinkman, H. and Hendrix, C. S. Occasional Paper $\mathrm{n}^{\circ} 24$. http://www.wfp.org/policy-resources (accessed 15.11.15).

Zhang, S., \& Liu, L. (2014). The potential of the MERIS Terrestrial Chlorophyll Index for crop yield prediction. Remote Sensing Letters, 5(8), 733-742. doi: 10.1080/2150704x.2014.963734 